\title{
A Higher-Order Thermomechanical Vibration Analysis of Temperature-Dependent FGM Beams with Porosities
}

\author{
Farzad Ebrahimi and Ali Jafari \\ Department of Mechanical Engineering, Faculty of Engineering, Imam Khomeini International University, Qazvin 34148-96818, Iran \\ Correspondence should be addressed to Farzad Ebrahimi; febrahimy@eng.ikiu.ac.ir
}

Received 3 November 2015; Accepted 17 February 2016

Academic Editor: Francis T. K. Au

Copyright (C) 2016 F. Ebrahimi and A. Jafari. This is an open access article distributed under the Creative Commons Attribution License, which permits unrestricted use, distribution, and reproduction in any medium, provided the original work is properly cited.

In the present paper, thermomechanical vibration characteristics of functionally graded (FG) Reddy beams made of porous material subjected to various thermal loadings are investigated by utilizing a Navier solution method for the first time. Four types of thermal loadings, namely, uniform, linear, nonlinear, and sinusoidal temperature rises, through the thickness direction are considered. Thermomechanical material properties of FG beam are assumed to be temperature-dependent and supposed to vary through thickness direction of the constituents according to power-law distribution (P-FGM) which is modified to approximate the porous material properties with even and uneven distributions of porosities phases. The governing differential equations of motion are derived based on higher order shear deformation beam theory. Hamilton's principle is applied to obtain the governing differential equations of motion which are solved by employing an analytical technique called the Navier type solution method. Influences of several important parameters such as power-law exponents, porosity distributions, porosity volume fractions, thermal effects, and slenderness ratios on natural frequencies of the temperature-dependent FG beams with porosities are investigated and discussed in detail. It is concluded that these effects play significant role in the thermodynamic behavior of porous FG beams.

\section{Introduction}

Functionally graded materials (FGMs) are advanced types of composite materials with inhomogeneous micromechanical structure, where the concentration, shape, and orientation of constituent phases vary in one or more directions optimizing the performance. Typically, FGMs are composed of two different parts such as ceramics with excellent characteristics in heat and corrosive resistances and metal with good toughness. Functional grading of the material properties is often in one direction. However, grading can be implemented in several directions. These materials have been developed for general purpose structural components such as rocket engine components or turbine blades where the components are exposed to extreme temperatures. The FGMs were introduced by Japanese scientists in mid-1980s as aerospace application for the first time. FGMs possess various advantages in comparison with traditional composites, for example, multifunctionality, ability to control deformation, corrosion resistance, dynamic response, minimization or remove stress concentrations, smoothing the transition of thermal stress, and resistance to oxidation. Hence, FGMs have received wide engineering applications in modern industries including aerospace, nuclear energy, turbine components, rocket nozzles, and critical furnace parts [1-4]. The advantages of using FGM structures in general engineering structures have been increasingly recognized in recent decades so it is important to understand behaviors of engineering structures made of FGM such as vibration, static, and dynamic behavior of the FG beams and plates often found in general engineering structures $[5,6]$.

A large number of investigations, dealing with static, buckling, and dynamic characteristics of FGM structures, are reported in literature. Aydogdu and Taskin [7] discussed free vibration analysis of simply supported FG beams with powerlaw and exponential material graduation. They used different higher-order shear deformation and classical beam theory (CBT) for deriving the differential equations of motion and solved them by Navier type solution method. Şimşek [8] investigated the vibration analysis of FGM beams using classical, the first-order, and different higher-order shear deformation beam theories. Various boundary conditions 
were considered. Pradhan and Chakraverty [9] have presented free vibration FG beams characteristics using Euler and Timoshenko beam theories. Rayleigh-Ritz method was used to obtain frequencies in their analysis. Thai and Vo [2] studied bending and free vibration of simply supported FG beams using various higher-order shear deformation beam theories. The Navier type solution method was used to solve equations.

Due to huge application of beams in different fields such as civil, marine, and aerospace engineering and difference between the making temperatures and working temperatures of structures, for more efficient design, it is important to take into account the thermal effect when designing FGM structures. Xiang and Yang [10] exploited free and forced vibrations and three-layered laminated FG Timoshenko beams with variable thickness in thermal environment. The beam was subjected to one-dimensional steady heat conduction in the thickness direction. Then, the equations of motion were then solved by using differential quadrature method. Mahi et al. [11] investigated temperature-dependent free vibration analysis of functionally graded beams with general boundary conditions. The important influence of temperature change on the vibration response of the FG beams is also taken into account. Fallah and Aghdam [12] investigated thermomechanical buckling and nonlinear vibration of FG beams on elastic foundation. They presented analytical closed form solutions and concluded that dependency of the constituents plays an important role in the vibration response of the FGM beams. Zhang [13] studied thermal postbuckling and nonlinear vibration of FG beams with using high order shear deformation theory and considering of physical neutral surface. He also used Ritz method for approximate solution of FG beams.

With the rapid progression in technology of structure elements, structures with graded porosity can be introduced as one of the latest developments in FGMs. The structures consider pores into microstructures by taking the local density into account. Moreover, a great opportunity in a wide range of engineering applications comes into result. One of the perfect candidates for structures under dynamic or impact loading is porous FGMs which have excellent energyabsorbing [14]. Researches have their eyes on development in preparation methods of FGMs such as powder metallurgy, vapor deposition, self-propagation, centrifugal casting, and magnetic separation [15-19]. These methods have their own disadvantages such as high costs and complexity of the technique. One of the flexible and suitable ways to manufacture FGM is sintering process. During this process, due to big difference in solidification between the material constituents, however, porosities or micro voids through material can happen regularly [20]. A thorough research has been done on porosities occurring inside FGM samples manufactured by a multistep sequential infiltration technique [3]. Porosity maybe change the elastic and mechanical properties. Based on this information about porosities in FGMs, it is important to consider the porosity effect when designing FGM structures.

Studies on the vibration response of porous FG structures, especially for beams, are still limited in number.
For porous plates and shells, the linear and nonlinear dynamic stability of a circular porous plate have been investigated to determine the critical loads in two separate studies by Magnucka-Blandzi [21, 22]. In another study, they also presented the problem of axisymmetrical deflection and buckling of circular porous plates [23]. Moreover, the wave propagation of an infinite $\mathrm{FG}$ plate having porosities by using various simple higher-order shear deformation theories has been studied by Yahia et al. [24]. Yahia et al. have presented nonlinear free vibrations analysis of FG porous annular plates resting on elastic foundations [24]. They concluded that porosity volume fraction and type of porosity distribution have a significant influence on the geometrically nonlinear free vibration response of the FG annular plates at large amplitudes. Mechab et al. have developed a nonlocal elasticity model for free vibration of FG porous nanoplates resting on elastic foundations [25]. They utilized exponential shear deformation plate theory. On the other hand, the dynamic stability of a porous cylindrical shell under different loading has been examined by Belica and Magnucki [26].

Wattanasakulpong and Ungbhakorn [27] investigated linear and nonlinear vibrations analyses of porous Euler FG beams with elastically restrained ends. Material properties of FG beam have been described by a modified rule of mixture. Ebrahimi and Mokhtari [28] studied transverse vibration analysis of rotating Timoshenko FG beams with porosities. DTM was presented to solve the equations of motion. It was concluded that porosity volume fractions play an important role in vibrations of porous FG beams. Moreover, Wattanasakulpong and Chaikittiratana [29] predicted flexural vibration of porous FG beams using Timoshenko beam theory. Chebyshev collection method was used for solving equations. They expressed the porosities yield reduction in the mass and strength of FG beams. Ebrahimi and Zia [30] investigated the large amplitude nonlinear vibration of porous FG Timoshenko beams. Galerkin and multiple scales methods were utilized to solve motion equations. Atmane et al. [31] used an efficient beam theory to study bending, free vibration, and buckling analysis of porous FG beams on elastic foundations. Literature search in the area of vibration analysis of FG porous beams indicated that there is no report considering the thermal environment effects on vibration characteristics of porous FG beams and the materials properties were assumed to be temperature independent. While one of the most important features of FGMs is thermal insulations, there is scientific need to be familiar with the thermomechanical behavior of FG porous structures subjected to thermal loading. Most recently, Ebrahimi et al. [32] studied the vibration of porous FG Euler beams subjected to thermal loading.

It should be noted that in, the abovementioned study, only one specific porosity distribution was considered and no detailed discussion concerning the effects of different porosity distributions on the thermomechanical vibration behavior of porous beams was given. Moreover, the sinusoidal temperature change is not considered. Also, they utilized EBT; it is well known that the EBT ignores the effect of shear deformation and rotary inertia of the thick beams. In other words, this theory is based on the assumption that plane 


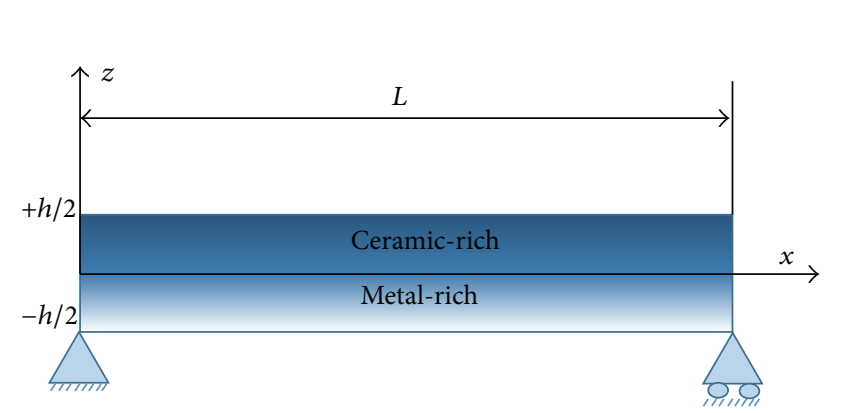

(a)

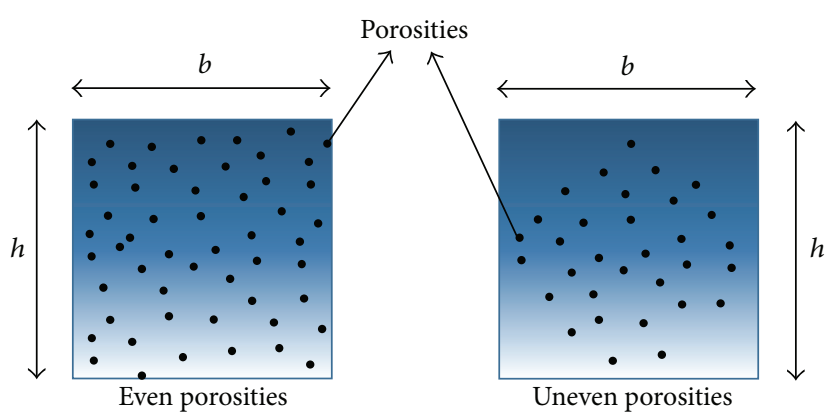

(b)

FIGURE 1: (a) Geometry and coordinates of functionally graded material beam. (b) Cross section area of FGM beam with even and uneven porosities.

sections of the cross section remain plane and perpendicular to the beam axis. The EBT is only suitable for vibration of thin beams; when a beam is moderately deep or made of highstrength composite materials with a high anisotropy ratio, the theory needs some modifications to include the effect of transverse shear.

Literature search in the area of vibration analyses of FG porous beams indicates that there is no report considering the thermal environment effects on vibration characteristics of porous FG beams based on higher-order shear deformation beam theory. Since thermal-barrier system is one of the applications to metallic-ceramic FGMs with porosities due to the gradual and smooth transition of material properties, there is scientific need to understand the thermomechanical vibration behavior of FG porous Reddy beams structures subjected to various thermal loadings. Reddy's higher-order shear deformation beam theory (RBT) can be used based on the assumption of the higher-order variation of axial displacement through the beam thickness. By confirming zero transverse shear stress conditions on the top and bottom surfaces of the beam, this theory considers both the microstructural and shear deformation effects without the need for any shear correction factors. In fact, to avoid the use of a shear correction factor and to have a better prediction of response of FG beams, higher-order shear deformation theories have been proposed, so that higher-order theories are quite attractive in the analysis of FG beams and plates [33]. Notable among higher-order theories is the third-order theory of Reddy $[2,8,34,35]$.

This paper focuses on the thermomechanical performance of porous FG beams subjected to various thermal loading with two different porosity distributions. These types of porosity distributions, namely, even and uneven, through the thickness directions are considered. Higherorder shear deformation beam theory is employed to account for the effect of transverse shear deformation and rotatory inertia. Four types of thermal loading, namely, uniform, linear, nonlinear, and sinusoidal temperature rises, trough the thickness direction are considered. An analytical solution is obtained for porous FG beams with simple support at both ends based on the Navier type solution. The material properties are assumed temperature-dependent and vary continuously through the thickness direction according to modified power-law form. Equations of motion and boundary condition have been derived by Hamilton's principle. These equations are solved by using Navier type method. A detailed parametric study is carried out to highlight the influence of thermal effects, gradient indexes, porosity volume fractions, types of porosity distribution, and aspect ratios on vibration behavior of FG Reddy beams with porosities. Comparisons between analytical solutions and the results from existing literature are provided for two-constituent metal-ceramic beams and good agreement between the results of this paper and those available in literature validated the presented approach. New numerical results can also be useful as valuable sources for validating other approaches and approximate methods.

Some novelties of the present study are stated as follows:

(i) Two different porosity distributions, namely, even and uneven, through the thickness directions are considered and the effects of different porosity parameters on the thermomechanical vibration of porous beams are given.

(ii) Higher-order shear deformation beam theory is employed to account for the effect of transverse shear deformation and rotatory inertia.

(iii) Various types of thermal loading including uniform, linear, nonlinear, and sinusoidal temperature rises are considered where this is the first time that sinusoidal temperature change is applied in the analysis of FG porous structures.

\section{Theory and Formulation}

2.1. Power-Low Functionally Graded Beams with Porosities. A uniform FG beam with porosities of length $L$, width $b$, and thickness $h$ is considered in this paper. As shown in Figure 1(a) $x$-axis is matched with neutral axis of the beam, the $y$-axis in the width direction, and the $z$-axis in the depth direction. The FG beam is made of porous materials with properties varying smoothly in the $z$ thickness direction. Top surface of FG beam $(z=h / 2)$ is assumed to be pure ceramics (materials with good resistance to heat), whereas 
the bottom surface $(z=-h / 2)$ is metal-rich (materials with good toughness property). Material properties of FG beams are supposed to vary through thickness direction of constitutes according to modified power-law distribution. Effective material properties such as Young's modulus $(E)$, mass density $(\rho)$, and thermal expansions $(\gamma)$ are assumed to vary continuously in the depth direction according to power-law. Poisson's ratio is assumed to be constant in the $z$-axis direction. The effective material properties of FG beams with two kinds of porosity distributions which are distributed identically in two phases of ceramic and metal can be expressed by using the modified rule of mixture as [27]

$$
p=P_{c}\left(v_{c}-\frac{a}{2}\right)+P_{m}\left(v_{m}-\frac{a}{2}\right)
$$

where $a$ is the volume fraction of porosities ( $a \ll 1)$, for perfect FGM, $a$ is set to zero, $P_{c}$ and $P_{m}$ are the material properties of ceramic and metal, and $v_{c}$ and $v_{m}$ are the volume fraction of ceramic and metal, respectively; the compositions are represented in relation to

$$
v_{c}+v_{m}=1
$$

Then, the volume fraction of ceramic $\left(v_{c}\right)$ can be written as follows:

$$
v_{c}=\left(\frac{z}{h}+\frac{1}{2}\right)^{n} \text {. }
$$

Here, $z$ is the distance from the mid-plane of the FGM beam and $n$ is the nonnegative variable parameter $(0 \leq n$, powerlaw exponent) which determines the material distribution through the thickness of the beams. According to this distribution, we have a fully metal beam for large values of $n$ and fully ceramic beam remains when $n$ equals zero. In this paper, imperfect FGM has been studied with two types of porosity distributions (even and uneven) across the beam thickness due to defect during fabrication.

For the even distribution of porosities (FGM-I), the effective material properties are obtained as follows:

$$
\begin{aligned}
& P(z)=\left(P_{c}-P_{m}\right)\left(\frac{z}{h}+\frac{1}{2}\right)^{n}+P_{m}-\frac{a}{2}\left(P_{c}+P_{m}\right) \\
& E(z)=\left(E_{c}-E_{m}\right)\left(\frac{z}{h}+\frac{1}{2}\right)^{n}+E_{m}-\frac{a}{2}\left(E_{c}+E_{m}\right) \\
& \rho(z)=\left(\rho_{c}-\rho_{m}\right)\left(\frac{z}{h}+\frac{1}{2}\right)^{n}+\rho_{m}-\frac{a}{2}\left(\rho_{c}+\rho_{m}\right) \\
& \gamma(z)=\left(\gamma_{c}-\gamma_{m}\right)\left(\frac{z}{h}+\frac{1}{2}\right)^{n}+\gamma_{m}-\frac{a}{2}\left(\gamma_{c}+\gamma_{m}\right) \\
& \kappa(z)=\left(\kappa_{c}-\kappa_{m}\right)\left(\frac{z}{h}+\frac{1}{2}\right)^{n}+\kappa_{m}-\frac{a}{2}\left(\kappa_{c}+\kappa_{m}\right),
\end{aligned}
$$

where the subscripts of $m, c$ denote the metal and ceramic constituents. For the second type, uneven distribution of porosities (defined as FGM-II), the effective material properties are replaced by the following form:

$$
\begin{aligned}
P(z)= & \left(P_{c}-P_{m}\right)\left(\frac{z}{h}+\frac{1}{2}\right)^{n}+P_{m} \\
& -\frac{a}{2}\left(P_{c}+P_{m}\right)\left(1-\frac{2|z|}{h}\right) \\
E(z)= & \left(E_{c}-E_{m}\right)\left(\frac{z}{h}+\frac{1}{2}\right)^{n}+E_{m} \\
& -\frac{a}{2}\left(E_{c}+E_{m}\right)\left(1-\frac{2|z|}{h}\right) \\
\rho(z)= & \left(\rho_{c}-\rho_{m}\right)\left(\frac{z}{h}+\frac{1}{2}\right)^{n}+\rho_{m} \\
& -\frac{a}{2}\left(\rho_{c}+\rho_{m}\right)\left(1-\frac{2|z|}{h}\right) \\
\gamma(z)= & \left(\gamma_{c}-\gamma_{m}\right)\left(\frac{z}{h}+\frac{1}{2}\right)^{n}+\gamma_{m} \\
& -\frac{a}{2}\left(\gamma_{c}+\gamma_{m}\right)\left(1-\frac{2|z|}{h}\right) \\
& -\frac{a}{2}\left(\kappa_{c}+\kappa_{m}\right)\left(1-\frac{2|z|}{h}\right) . \\
\kappa(z)= & \left(\kappa_{c}-\kappa_{m}\right)\left(\frac{z}{h}+\frac{1}{2}\right)^{n}+\kappa_{m} \\
&
\end{aligned}
$$

Here, it should be noted that the FGM-I has porosity phases with even distribution of volume fraction over the cross section, while the FGM-II has porosity phases spreading frequently nearby the middle zone of the cross section and the amount of porosity seems to be linearly decreased to zero at the top and bottom of the cross section. Figure 1(b) shows examples of cross section areas of FGM-I and FGM-II with porosity phases.

To predict the behavior of FGMs under high temperature more accurately, it is necessary to consider the temperature dependency on material properties. The nonlinear equation of thermoelastic material properties in function of temperature $T(\mathrm{~K})$ can be expressed as [36]:

$$
P=P_{0}\left(P_{-1} T^{-1}+1+P_{1} T+P_{2} T^{2}+P_{3} T^{3}\right),
$$

where $P_{0}, P_{-1}, P_{1}, P_{2}$, and $P_{3}$ are the temperature-dependent coefficients which can be seen in Table 1 materials properties for $\mathrm{Si}_{3} \mathrm{~N}_{4}$ and SUS304. The bottom surface $(z=-h / 2)$ of FG porous beam is pure metal (SUS304), whereas the top surface $(z=h / 2)$ is pure ceramics $\left(\mathrm{Si}_{3} \mathrm{~N}_{4}\right)$.

2.2. Kinematic Relations. The equations of motion are derived based on third-order shear deformation (Reddy) beam theory; the displacement field Reddy beam theory at any point of the beam can be written as 
TABLE 1: Temperature-dependent coefficients of Young's modulus, thermal expansion coefficient, mass density, and Poisson's ratio for $\mathrm{Si}_{3} \mathrm{~N}_{4}$ and SUS304.

\begin{tabular}{|c|c|c|c|c|c|c|}
\hline Material & Properties & $P_{0}$ & $P_{-1}$ & $P_{1}$ & $P_{2}$ & $P_{3}$ \\
\hline \multirow{4}{*}{$\mathrm{Si}_{3} \mathrm{~N}_{4}$} & $E(\mathrm{~Pa})$ & $348.43 e+9$ & 0 & $-3.070 e-4$ & $2.160 e-7$ & $-8.946 e-11$ \\
\hline & $\gamma\left(\mathrm{K}^{-1}\right)$ & $5.8723 e-6$ & 0 & $9.095 e-4$ & 0 & 0 \\
\hline & $\rho\left(\mathrm{Kg} / \mathrm{m}^{3}\right)$ & 2370 & 0 & 0 & 0 & 0 \\
\hline & $v$ & 0.24 & 0 & 0 & 0 & 0 \\
\hline \multirow{4}{*}{ SUS304 } & $E(\mathrm{~Pa})$ & $201.04 e+9$ & 0 & $3.079 e-4$ & $-6.534 e-7$ & 0 \\
\hline & $\gamma\left(\mathrm{K}^{-1}\right)$ & $12.330 e-6$ & 0 & $8.086 e-4$ & 0 & 0 \\
\hline & $\rho\left(\mathrm{Kg} / \mathrm{m}^{3}\right)$ & 8166 & 0 & 0 & 0 & 0 \\
\hline & $v$ & 0.3262 & 0 & $-2.002 e-4$ & $3.797 e-7$ & 0 \\
\hline
\end{tabular}

$$
\begin{aligned}
& u_{x}(x, z, t)=u(x, t)+z \varphi(x, t)-\alpha z^{3}\left(\varphi+\frac{\partial w}{\partial x}\right) \\
& u_{y}(x, z, t)=0 \\
& u_{z}(x, z, t)=w(x, t)
\end{aligned}
$$

where

$$
\begin{aligned}
& \alpha=\frac{4}{3 h^{2}}, \\
& (\beta=3 \alpha)
\end{aligned}
$$

in which $x$-, $y$-, and $z$-coordinates are taken along the length, width, and height of the beam, respectively. And $u$ is the axial displacement of mid-plane along $x$-axis, $w$ is the transverse displacement along $z$-axis, $\varphi$ is the angle of rotational of cross section due to bending, and $t$ is the time. Then, the strains displacement relation of Reddy beam theory can be expressed as

$$
\begin{aligned}
& \varepsilon_{x x}=\frac{\partial u}{\partial x}+z \frac{\partial \varphi}{\partial x}-\alpha z^{3}\left(\frac{\partial \varphi}{\partial x}+\frac{\partial^{2} w}{\partial x^{2}}\right) \\
& \gamma_{x z}=\frac{\partial w}{\partial x}+\varphi-\beta z^{2}\left(\varphi+\frac{\partial w}{\partial x}\right) .
\end{aligned}
$$

$\varepsilon_{x x}$ and $\gamma_{x z}$ are normal and shear strain. The Euler-Lagrange equation is used to derive the equation of motion by using a Hamilton's principle, which can be stated as

$$
\int_{t_{1}}^{t_{2}} \delta(U-T+V) d t=0
$$

where $t_{1}$ and $t_{2}$ are the initial and end time $\delta U$ is the virtual variation of strain energy, $\delta V$ is the virtual variation of work done by external loads, and $\delta T$ is the virtual variation of kinetic energy. Here, strain energy, kinetic energy, and potential energy (external loading) can be calculated step by step and the equations of motion are obtained by using rules of calculus of variations and Hamilton's principle. The first variation of the virtual strain energy can be written in the form:

$$
\begin{aligned}
\delta U & =\int_{v} \sigma_{i j} \delta \varepsilon_{i j} d V \\
& =\int_{A} \int_{0}^{L}\left(\sigma_{x x} \delta \varepsilon_{x x}+\sigma_{x z} \delta \gamma_{x z}\right) d x d A,
\end{aligned}
$$

where $\delta$ is the variation symbol, $A$ is the cross section area of the uniform beam, $\sigma_{x x}$ is the axial stress, and $\sigma_{x z}$ is the shear stress, by substituting the expressions for $\varepsilon_{x x}$ and $\gamma_{x z}$ into (13) as

$$
\begin{aligned}
\delta U & =\int_{0}^{L} \int_{A} \sigma_{x x} \delta\left[\frac{\partial u}{\partial x}+z \frac{\partial \varphi}{\partial x}\right. \\
& \left.-\alpha z^{3}\left(\frac{\partial \varphi}{\partial x}+\frac{\partial^{2} w}{\partial x^{2}}\right)\right] d A d x \\
& +\int_{0}^{L} \int_{A} \sigma_{x z} \delta\left[\left(\frac{\partial w}{\partial x}+\varphi\right)\right. \\
& \left.-\beta z^{2}\left(\frac{\partial w}{\partial x}+\varphi\right)\right] d A d x
\end{aligned}
$$

Then, the usual bending moment $M$, axial force $N$, shear force $Q$, and higher-order stress resultants $P$ and $R$ are defined as in the following and by replacing these resultants into (14) as following:

$$
\begin{aligned}
& (N, M, P)=\int_{A} \sigma_{x x}\left(1, z, z^{3}\right) d A \\
& (Q, R)=\int_{A} \sigma_{x z}\left(1, z^{2}\right) d A \\
& \delta U=\int_{0}^{L}\left[-\frac{\partial N}{\partial x} \delta u+\frac{\partial M}{\partial x} \delta \varphi-\alpha \frac{\partial P}{\partial x} \delta \varphi+\alpha \frac{\partial^{2} P}{\partial x^{2}}\right. \\
& \left.\quad+\frac{\partial Q}{\partial x} \delta w-Q \delta \varphi+\beta R \delta \varphi-\beta \frac{\partial R}{\partial x} \delta w\right] d x .
\end{aligned}
$$

The kinetic energy expression for Timoshenko beam theory can be expressed as

$$
\begin{aligned}
T & =\frac{1}{2} \int_{0}^{L} \int_{A} \rho(z, T)\left(\left(\frac{\partial u_{x}}{\partial t}\right)^{2}+\left(\frac{\partial u_{y}}{\partial t}\right)^{2}\right. \\
& \left.+\left(\frac{\partial u_{z}}{\partial t}\right)^{2}\right) d A d x \\
T & =\frac{1}{2} \int_{0}^{L} \int_{A} \rho(Z, T)\left[\left(\frac{\partial u}{\partial t}\right)^{2}+z^{2}\left(\frac{\partial \varphi}{\partial t}\right)^{2}\right.
\end{aligned}
$$




$$
\begin{aligned}
& +\alpha^{2} z^{6}\left[\left(\frac{\partial \varphi}{\partial t}\right)^{2}+\left(\frac{\partial^{2} w}{\partial x \partial t}\right)^{2}+2 \frac{\partial \varphi}{\partial t} \frac{\partial^{2} w}{\partial x \partial t}\right] \\
& +2 z \frac{\partial \varphi}{\partial t} \frac{\partial u}{\partial t}-2 \frac{\partial u}{\partial t} \alpha z^{3}\left(\frac{\partial \varphi}{\partial t}+\frac{\partial^{2} w}{\partial x \partial t}\right) \\
& \left.-2 \frac{\partial \varphi}{\partial t} \alpha z^{4}\left(\frac{\partial \varphi}{\partial t}+\frac{\partial^{2} w}{\partial x \partial t}\right)+\left(\frac{\partial w}{\partial t}\right)^{2}\right]
\end{aligned}
$$

The first variation of the virtual kinetic energy can be written in the form:

$$
\begin{aligned}
\delta T & =\frac{1}{2} \int_{0}^{L}\left[I_{0}\left(\frac{\partial^{2} u}{\partial t^{2}}\right) \delta u+I_{2}\left(\frac{\partial^{2} \varphi}{\partial t^{2}}\right) \delta \varphi\right. \\
& +\alpha^{2} I_{6}\left[\left(\frac{\partial^{2} \varphi}{\partial t^{2}}\right) \delta \varphi+\left(\frac{\partial^{4} w}{\partial x^{2} \partial t^{2}}\right) \delta w+\frac{\partial^{3} w}{\partial x \partial t^{2}} \delta \varphi\right. \\
& \left.+\frac{\partial^{3} \varphi}{\partial x \partial t^{2}} \delta w\right]+I_{1} \frac{\partial^{2} u}{\partial t^{2}} \delta \varphi+I_{1} \frac{\partial^{2} \varphi}{\partial t^{2}} \delta u \\
& -\alpha I_{3}\left[\left(\frac{\partial^{2} \varphi}{\partial t^{2}}+\frac{\partial^{3} w}{\partial x \partial t^{2}}\right) \delta u+\frac{\partial^{2} u}{\partial t^{2}} \delta \varphi+\frac{\partial^{3} u}{\partial x \partial t^{2}} \delta w\right] \\
& -\alpha I_{4}\left[\frac{\partial^{2} \varphi}{\partial t^{2}} \delta \varphi+\frac{\partial^{3} w}{\partial x \partial t^{2}} \delta \varphi+\frac{\partial^{3} \varphi}{\partial x \partial t^{2}} \delta w\right]+I_{0} \frac{\partial^{2} w}{\partial t^{2}} \\
& \cdot \delta w] d x,
\end{aligned}
$$

where $\left(I_{0}, I_{1}, I_{2}, I_{3}, I_{4}, I_{5}, I_{6}\right)$ are the mass moments of inertias that can be written as follows:

$$
\begin{aligned}
& \left(I_{0}, I_{1}, I_{2}, I_{3}, I_{4}, I_{5}, I_{6}\right) \\
& \quad=\int_{A} \rho(z, T)\left(1, z, z^{2}, z^{3}, z^{4}, z^{5}, z^{6}\right) d A .
\end{aligned}
$$

Also, the first variation of potential energy can be written in the form:

$$
\delta V=\int_{0}^{L} N^{T} \frac{\partial w}{\partial x} \frac{\partial(\delta w)}{\partial x} d x
$$

where $N^{T}$ is defined as in the following:

$$
N^{T}=\int E(z, T) \gamma(z, T) \Delta T d z
$$

in which $\gamma(z, T)$ is the coefficient of thermal dilatation that is typically positive and very small.
The equation of motion derived from Hamilton's principle can be expressed as follows:

$$
\begin{gathered}
\frac{\partial N}{\partial x}=I_{0} \frac{\partial^{2} u}{\partial t^{2}}+\bar{I}_{1} \frac{\partial^{2} \varphi}{\partial t^{2}}-\alpha I_{3} \frac{\partial^{3} w}{\partial x \partial t^{2}}=0, \quad(\delta u: 0) \\
\frac{\partial \bar{M}}{\partial x}-\bar{Q}=\bar{I}_{1} \frac{\partial^{2} u}{\partial t^{2}}+\bar{I}_{2} \frac{\partial^{2} \varphi}{\partial t^{2}}-\alpha \bar{I}_{4}\left(\frac{\partial^{2} \varphi}{\partial t^{2}}+\frac{\partial^{3} w}{\partial x \partial t^{2}}\right) \\
=0, \quad(\delta \varphi: 0) \\
\frac{\partial \bar{Q}}{\partial x}-N^{T} \frac{\partial^{2} w}{\partial x^{2}}+\alpha \frac{\partial^{2} p}{\partial x^{2}} \\
=I_{0} \frac{\partial^{2} w}{\partial t^{2}}+\alpha I_{3} \frac{\partial^{3} u}{\partial x \partial t^{2}}+\alpha I_{4} \frac{\partial^{3} \varphi}{\partial x \partial t^{2}} \\
\quad-\alpha^{2} I_{6}\left(\frac{\partial^{4} w}{\partial x^{2} \partial t^{2}}+\frac{\partial^{3} \varphi}{\partial x \partial t^{2}}\right)=0, \quad(\delta w: 0),
\end{gathered}
$$

where

$$
\begin{aligned}
& \bar{I}_{1}=I_{1}-\alpha I_{3}, \\
& \bar{I}_{2}=I_{2}-\alpha I_{4}, \\
& \bar{I}_{4}=I_{4}-\alpha I_{6}, \\
& \bar{Q}=Q-\beta R, \\
& \bar{M}=M-\alpha P .
\end{aligned}
$$

The formulation is limited to linear elastic material behavior. For a material that is linearly elastic and obeys the 1D Hooke's law, the relation between stress and strain is defined as

$$
\begin{aligned}
& \sigma_{x x}=E(z, T) \varepsilon_{x x} \\
& \sigma_{x z}=G(z, T) \gamma_{x z},
\end{aligned}
$$

where $G(z)$ is the shear modulus $(G(z, T)=E(z, T) / 2(1+$ $v))$ and $E(z, T)$ is Young's modulus. By substituting (9) and (10) into (14) and integrating over the beam's cross section, bending moment, axial force, shear force, and higher-order stress resultants can be derived as in the following:

$$
\begin{aligned}
& N=A_{x x} \frac{\partial u}{\partial x}+\left[B_{x x}-\alpha D_{x x}\right] \frac{\partial \varphi}{\partial x}-\alpha D_{x x} \frac{\partial^{2} w}{\partial x^{2}} \\
& M=B_{x x} \frac{\partial u}{\partial x}+\left[C_{x x}-\alpha E_{x x}\right] \frac{\partial \varphi}{\partial x}-\alpha E_{x x} \frac{\partial^{2} w}{\partial x^{2}}
\end{aligned}
$$

$$
\begin{aligned}
& P=D_{x x} \frac{\partial u}{\partial x}+\left[E_{x x}-\alpha G_{x x}\right] \frac{\partial \varphi}{\partial x}-\alpha G_{x x} \frac{\partial^{2} w}{\partial x^{2}} \\
& Q=\left[A_{x z}-\beta C_{x z}\right]\left(\varphi+\frac{\partial w}{\partial x}\right) \\
& R=\left[C_{x z}-\beta E_{x z}\right]\left(\varphi+\frac{\partial w}{\partial x}\right)
\end{aligned}
$$


in which the cross section stiffness is defined as

$$
\begin{gathered}
\left(A_{x x}, B_{x x}, C_{x x}, D_{x x}, E_{x x}, G_{x x}\right) \\
=\int_{A}\left(1, z, z^{2}, z^{3}, z^{4}, z^{6}\right) E(z) d A \\
A_{x z}, C_{x z}, E_{x z}=\int_{A} G(z)\left(1, z^{2}, z^{4}\right) d A .
\end{gathered}
$$

And the last form of Euler-Lagrange equations for FG Reddy beam theory with porosities subjected to various types of thermal loading in terms of displacements $u, \varphi$, and $w$ can be derived as

$$
\begin{gathered}
A_{x x} \frac{\partial^{2} u}{\partial x^{2}}+\bar{B}_{x x} \frac{\partial^{2} \varphi}{\partial x^{2}}-\alpha D_{x x} \frac{\partial^{3} w}{\partial x^{3}}=I_{0} \frac{\partial^{2} u}{\partial t^{2}}+I_{1} \frac{\partial^{2} \varphi}{\partial t^{2}} \\
-\alpha I_{3}\left(\frac{\partial^{2} \varphi}{\partial t^{2}}+\frac{\partial^{3} w}{\partial x \partial t^{2}}\right) \\
\bar{B}_{x x} \frac{\partial^{2} u}{\partial x^{2}}+\bar{C}_{x x} \frac{\partial^{2} \varphi}{\partial x^{2}}-\alpha \bar{E}_{x x}\left(\frac{\partial^{3} w}{\partial x^{3}}+\frac{\partial^{2} \varphi}{\partial x^{2}}\right) \\
-j_{1}\left(\varphi+\frac{\partial w}{\partial x}\right)=\bar{I}_{1} \frac{\partial^{2} u}{\partial t^{2}}+\bar{I}_{2} \frac{\partial^{2} \varphi}{\partial t^{2}} \\
-\alpha \bar{I}_{4}\left(\frac{\partial^{2} \varphi}{\partial t^{2}}+\frac{\partial^{3} w}{\partial x \partial t^{2}}\right) \\
j_{1}\left(\frac{\partial^{2} w}{\partial x^{2}}+\frac{\partial \varphi}{\partial x}\right)-N^{T} \frac{\partial^{2} w}{\partial x^{2}}+\alpha D_{x x} \frac{\partial^{3} u}{\partial x^{3}}+\alpha \bar{E}_{x x} \frac{\partial^{3} \varphi}{\partial x^{3}} \\
-\alpha^{2} G_{x x} \frac{\partial^{4} w}{\partial x^{4}}=I_{0} \frac{\partial^{2} w}{\partial t^{2}}+\alpha I_{3} \frac{\partial^{3} u}{\partial x \partial t^{2}}+\alpha I_{4} \frac{\partial^{3} \varphi}{\partial x \partial t^{2}} \\
-\alpha^{2} I_{6}\left(\frac{\partial^{4} w}{\partial x^{2} \partial t^{2}}+\frac{\partial^{3} \varphi}{\partial x \partial t^{2}}\right),
\end{gathered}
$$

where

$$
\begin{gathered}
\bar{B}_{x x}=B_{x x}-\alpha D_{x x}, \\
\bar{C}_{x x}=C_{x x}-\alpha E_{x x}, \\
\bar{E}_{x x}=E_{x x}-\alpha G_{x x} \\
\bar{A}_{x z}=A_{x z}-\beta C_{x z}, \\
\bar{C}_{x z}=C_{x z}-\beta E_{x z}, \\
j_{1}=\bar{A}_{x z}-\beta \bar{C}_{x z} .
\end{gathered}
$$

\section{Solution Method}

3.1. Analytical Solution. In this section, an analytical solution of the Euler-Lagrange equations for free vibration of simply supported porous FG beam based on Navier type method is presented. The displacement functions are expressed as combinations of nonsignificant coefficients and known trigonometric functions to satisfy Lagrange equations and boundary conditions at $x=0, x=L$. The following displacements functions are assumed to be formed:

$$
\begin{aligned}
& u(x, t)=\sum_{m=1}^{\infty} u_{m} \cos \left(\frac{m \pi}{L} x\right) e^{i w_{m} t} \\
& w(x, t)=\sum_{m=1}^{\infty} w_{m} \sin \left(\frac{m \pi}{L} x\right) e^{i w_{m} t} \\
& \varphi(x, t)=\sum_{m=1}^{\infty} \varphi_{m} \cos \left(\frac{m \pi}{L} x\right) e^{i w_{m} t}
\end{aligned}
$$

in which $\left(u_{m}, w_{m}, \varphi_{m}\right)$ are the unknown Fourier coefficients that will be calculated for each value of $m$. Boundary conditions for a simply supported beam are as follows [37]:

$$
\begin{aligned}
u(0) & =0, \\
\frac{\partial u}{\partial x}(L) & =0 \\
w(0) & =w(L)=0, \\
\frac{\partial \varphi}{\partial x}(0) & =\frac{\partial \varphi}{\partial x}(L)=0 .
\end{aligned}
$$

Substituting $((31)-(33))$ into $((27)-(29))$, respectively, leads to $((35)-(37))$ :

$$
\begin{aligned}
& \left(-\bar{A}_{x x}\left(\frac{m \pi}{L}\right)^{2}+I_{0} \omega_{m}{ }^{2}\right) u_{m}+\left(-\bar{B}_{x x}\left(\frac{m \pi}{L}\right)^{2}\right. \\
& \left.+\bar{I}_{1} \omega_{m}{ }^{2}\right) \varphi_{m}+\left(\alpha D_{x x}\left(\frac{m \pi}{L}\right)^{3}-\alpha I_{3} \omega_{m}{ }^{2}\left(\frac{m \pi}{L}\right)\right) \\
& \cdot w_{m}=0 \\
& \left(-\bar{B}_{x x}\left(\frac{m \pi}{L}\right)^{2}+\bar{I}_{1} \omega^{2}\right) u_{m}+\left(-\bar{C}_{x x}\left(\frac{m \pi}{L}\right)^{2}\right. \\
& \left.+\alpha \bar{E}_{x x}\left(\frac{m \pi}{L}\right)^{2}-j_{1}+\left(\bar{I}_{2}-\alpha \bar{I}_{4}\right) \omega_{m}^{2}\right) \varphi_{m} \\
& +\left(\alpha E_{x x}\left(\frac{m \pi}{L}\right)^{3}-j_{1}\left(\frac{m \pi}{L}\right)-\alpha \bar{I}_{4}\left(\frac{m \pi}{L}\right) \omega_{m}{ }^{2}\right) \\
& \cdot w_{m}=0 \\
& \left(\alpha D_{x x}\left(\frac{m \pi}{L}\right)^{3}-\alpha I_{3} \omega_{m}{ }^{2}\left(\frac{m \pi}{L}\right)\right) u_{m} \\
& +\left(\alpha E_{x x}\left(\frac{m \pi}{L}\right)^{3}-j_{1}\left(\frac{m \pi}{L}\right)-\alpha \bar{I}_{4}\left(\frac{m \pi}{L}\right) \omega_{m}{ }^{2}\right) \\
& \cdot \varphi_{m}+\left(-j_{1}\left(\frac{m \pi}{L}\right)^{2}+N t\left(\frac{m \pi}{L}\right)^{2}\right. \\
& \left.+\alpha^{2} G_{x x}\left(\frac{m \pi}{L}\right)^{4}+I_{0} \omega_{m}{ }^{2}+\alpha^{2} I_{6}\left(\frac{m \pi}{L}\right)^{2} \omega_{m}{ }^{2}\right) \\
& \text { - } W_{m}=0 \text {. }
\end{aligned}
$$


By finding determinant of the coefficient matrix of the above equations and setting this multinomial to zero, we can find natural frequencies $\omega_{n}$ :

$$
\operatorname{det}\left(\begin{array}{lll}
a_{11} & a_{12} & a_{13} \\
a_{21} & a_{22} & a_{23} \\
a_{31} & a_{32} & a_{33}
\end{array}\right)=0
$$

where

$$
\begin{aligned}
& a_{11}=\left(-\bar{A}_{x x}\left(\frac{m \pi}{L}\right)^{2}+I_{0} \omega_{m}^{2}\right), \\
& a_{12}=\left(-\bar{B}_{x x}\left(\frac{m \pi}{L}\right)^{2}+\bar{I}_{1} \omega_{m}^{2}\right), \\
& a_{13}=\left(\alpha D_{x x}\left(\frac{m \pi}{L}\right)^{3}-\alpha I_{3} \omega_{m}^{2}\left(\frac{m \pi}{L}\right)\right) \\
& a_{21}=\left(-\bar{B}_{x x}\left(\frac{m \pi}{L}\right)^{2}+\bar{I}_{1} \omega^{2}\right) \\
& a_{22}=\left(-\bar{C}_{x x}\left(\frac{m \pi}{L}\right)^{2}+\alpha \bar{E}_{x x}\left(\frac{m \pi}{L}\right)^{2}-j_{1}\right. \\
& \left.+\left(\bar{I}_{2}-\alpha \bar{I}_{4}\right) \omega_{m}^{2}\right) \\
& a_{23}=\left(\alpha E_{x x}\left(\frac{m \pi}{L}\right)^{3}-j_{1}\left(\frac{m \pi}{L}\right)-\alpha \bar{I}_{4}\left(\frac{m \pi}{L}\right) \omega_{m}^{2}\right) \\
& a_{31}=\left(\alpha D_{x x}\left(\frac{m \pi}{L}\right)^{3}-\alpha I_{3} \omega_{m}^{2}\left(\frac{m \pi}{L}\right)\right) \text {, } \\
& a_{32}=\left(\alpha E_{x x}\left(\frac{m \pi}{L}\right)^{3}-j_{1}\left(\frac{m \pi}{L}\right)-\alpha \bar{I}_{4}\left(\frac{m \pi}{L}\right) \omega_{m}{ }^{2}\right) \text {, } \\
& a_{33}=\left(-j_{1}\left(\frac{m \pi}{L}\right)^{2}+N t\left(\frac{m \pi}{L}\right)^{2}+\alpha^{2} G_{x x}\left(\frac{m \pi}{L}\right)^{4}\right. \\
& \left.+I_{0} \omega_{m}^{2}+\alpha^{2} I_{6}\left(\frac{m \pi}{L}\right)^{2} \omega_{m}^{2}\right) \text {. }
\end{aligned}
$$

\section{Thermal Environment and Temperature Distributions}

For a porous FG beam in thermal environment, temperature is assumed to vary along the thickness directions at four ways as follows.

4.1. Uniform Temperature Rise (UTR). Consider a porous FG that is at initial temperature equal to $T_{0}=300$ and beam is free of stresses at initial temperature and temperature of beam changes to final temperature with the difference of $\Delta T$ as

$$
\Delta T=T-T_{0}
$$

4.2. Linear Temperature Rise (LTR). Consider that the temperature of the top surface (ceramic-rich) of the porous FG beam is $T_{c}$ and varies linearly from $T_{c}$ to the bottom surface (metal-rich) temperature $T_{m}$. Finally, the temperature rise as a function of thickness is given as [38]

$$
T=T_{m}+\Delta T\left(\frac{1}{2}+\frac{z}{h}\right) .
$$

And $\Delta T$ should be defined as

$$
\Delta T=T_{c}-T_{m}
$$

4.3. Nonlinear Temperature Rise (NLTR). In this case, nonlinear temperature rise across the thickness is assumed. The steady-state one-dimensional heat conduction equation with the known temperature boundary conditions on bottom and top surfaces of the FG nanobeam can be obtained by solving the following equation [13]:

$$
\begin{aligned}
-\frac{d}{d z}\left(\kappa(z, T) \frac{d T}{d z}\right) & =0 \\
T\left(\frac{h}{2}\right) & =T_{c}, \\
T\left(-\frac{h}{2}\right) & =T_{m} .
\end{aligned}
$$

The solution of (43) subjected to the boundary conditions can be solved by the following equation:

$$
T=T_{m}+(\Delta T) \frac{\int_{-h / 2}^{z}(1 / \kappa(z, T)) d z}{\int_{-h / 2}^{h / 2}(1 / \kappa(z, T)) d z},
$$

where $\Delta T=T_{c}-T_{m}$.

4.4. Sinusoidal Temperature Rise (STR). The temperature field when FG beam is exposed to sinusoidal temperature rise across the thickness can be defined as [39]

$$
T=T_{m}+\Delta T\left(1-\cos \frac{\pi}{2}\left(\frac{1}{2}+\frac{z}{h}\right)\right),
$$

where $\Delta T=T_{c}-T_{m}$ is temperature change.

\section{Numerical Result and Discussions}

Through this section, after validation of the proposed method of solution, the influence of different beam parameters such as porosity distribution, porosity volume fraction, powerlaw exponent, temperature changes, and slenderness on the natural frequencies of the porous FG beam under uniform, linear, nonlinear, and sinusoidal temperature rise across the thickness direction will be perceived.

The functionally graded porous beam is a combination of steel (SUS304) and silicon nitride $\left(\mathrm{Si}_{3} \mathrm{~N}_{4}\right)$ where its properties are given in Table 1. It is assumed that the temperature increase in metal surface to reference temperature $T_{0}$ of the FG beam is $T_{m}-T_{0}=5 \mathrm{~K}[38]$.

The nondimensional natural frequencies $(\bar{\omega})$ can be calculated by relations in the following:

$$
\bar{\omega}=\omega \frac{L^{2}}{h} \sqrt{\frac{\rho_{m}}{e_{m}}} .
$$


TABLE 2: Comparison of the nondimensional fundamental frequency for S-S FG beam with various gradient indexes.

\begin{tabular}{|c|c|c|c|c|}
\hline \multirow{2}{*}{ Power-law exponent } & \multirow{2}{*}{$L / h$} & Present & Şimşek [8] & Thai and Vo [2] \\
\hline & & Analytical & Lagrange's equations & Analytical \\
\hline \multirow{2}{*}{$n=0$} & 5 & 5.1527478 & 5.15274 & 5.1527 \\
\hline & 20 & 5.4603201 & 5.46030 & 5.4603 \\
\hline \multirow{2}{*}{$n=0.2$} & 5 & 4.8080746 & 4.80924 & - \\
\hline & 20 & 5.0815249 & 5.08286 & - \\
\hline \multirow{2}{*}{$n=0.5$} & 5 & 4.4106620 & 4.41108 & 4.4111 \\
\hline & 20 & 4.6511086 & 4.65159 & 4.6516 \\
\hline \multirow{2}{*}{$n=1$} & 5 & 3.9904189 & 3.99042 & 3.9904 \\
\hline & 20 & 4.2050549 & 4.20503 & 4.2050 \\
\hline \multirow{2}{*}{$n=2$} & 5 & 3.6264396 & 3.62643 & 3.6264 \\
\hline & 20 & 3.8361340 & 3.83611 & 3.8361 \\
\hline \multirow{2}{*}{$n=5$} & 5 & 3.4012044 & 3.40120 & 3.4012 \\
\hline & 20 & 3.6484863 & 3.64850 & 3.6485 \\
\hline \multirow{2}{*}{$n=10$} & 5 & 3.2816047 & 3.28160 & 3.2816 \\
\hline & 20 & 3.5389891 & 3.53896 & 3.5390 \\
\hline \multirow{2}{*}{ Full metal } & 5 & 2.66086 & 2.67732 & - \\
\hline & 20 & 2.83602 & 2.83716 & - \\
\hline
\end{tabular}

To verify the accuracy of the present method, the numerical results obtained will be compared with those available in the literature to demonstrate the performance of the present study. For this purpose, fundamental dimensionless frequencies of simply FG beams are compared with those of Şimşek [8] and Thai and Vo [2] for different volume fraction index and slenderness. The FG beam made of alumina and aluminum is compared with results of Simsek and Thai which have been obtained by using Lagrange's equations and Navier type solution. Computations have been carried out for the following material and beam properties: $\left(E_{\mathrm{Al}}=\right.$ $70 \mathrm{GPa}, \rho_{\mathrm{Al}}=2702 \mathrm{~kg} / \mathrm{m}^{3}, v_{\mathrm{Al}}=0.3, E_{\mathrm{Al}_{2} \mathrm{O}_{3}}=380 \mathrm{GPa}$, $\left.\rho_{\mathrm{Al}_{2} \mathrm{O}_{3}}=3960 \mathrm{~kg} / \mathrm{m}^{3}, v_{\mathrm{Al}_{2} \mathrm{O}_{3}}=0.3\right)$ for $L / h=(5,20)$. By studying Table 2, it is observed that the fundamental frequency parameters obtained in the present investigation are in good agreement with the results provided in these literatures and thus validate the proposed method of solution.

In the present section, results are extracted for various temperature changes, power-law indexes, porosity parameters with four temperature rises (UTR, LTR, NLTR, and STR), and two porosity distributions (even, uneven) to present an adequate sensitivity analysis.

As a first verification and investigation example, effects of porosity parameter, thermal loading, porosity distribution, and power-law exponents on the first nondimensional natural frequency of the porous FG simply supported beams are assessed. In Table 3, the first dimensionless natural frequencies of the simply supported porous FG beams subjected to UTR, LTR, NLTR, and STR are presented for various values of the gradient index $(n=0.1,0.2,0.5$, and 1$)$, volume fraction of porosity ( $a=0,0.1$, and 0.2$)$, and three different values of temperature changes $(\Delta t=20,40$, and $80 \mathrm{~K})$ for $L / h=20$ based on analytical solution method. Two types of porosity distributions are considered (even and uneven), and temperature risings are inclusive uniform, linear, nonlinear and sinusoidal distributions. Present results are derived using Navier type solution method.

Results given in Table 3 show that increasing the powerlaw exponents leads to a decrease in the nondimensional frequencies. In fact, when $n=0$, beam is made fully from ceramics and has the greatest frequency. Increasing the power-law exponents from 0 to 5 changes the composition of the FG beam from a fully ceramic beam to a beam with a combination of ceramic and metal. So by increasing the metal percentage and having the smaller value of Young's modulus in metal with respect to ceramic, the stiffness of the system decreases. Thus, as also known from mechanical vibrations, natural frequencies decrease as the stiffness of a structure decreases. In addition, it is obvious from this table that increasing temperature change (UTR, LTR, NLTR, and STR) yields decreasing of natural frequencies, indicating that increasing of temperature changes yields decreasing of Young's modulus $\mathrm{E}$ and a rise in temperature increases this effect. It is concluded that four temperature rises have a significant effect on the fundamental FG porous beam. It is deduced that the nondimensional frequency of FG porous beams under sinusoidal temperature rise is higher than that under nonlinear temperature rise, and the frequency of the FG porous beam subjected to NLTR is higher than that of FG porous beam subjected to LTR, in which the frequency of the FG porous beam subjected to LTR is higher than that subjected to UTR. Also, the difference between nondimensional frequencies of different temperature rises (UTR, LTR, NLTR, and STR) becomes larger by increasing the temperature changes. The reason is that the rigidity of the FG beam for sinusoidal temperature rise is the greatest among the other cases of temperature rises. It is evident from the results of the table that when the power-law indexes are in the range of [0-1], the natural frequencies grow with the increase in the porosity parameters for every temperature rising and porosity distribution, because of internal pores growth rigidity of the 
TABLE 3: Temperature and material graduation effect on first dimensionless natural frequency of S-S FG porous beam with different FG type and porosity parameter and thermal loading $(L / h=20)$.

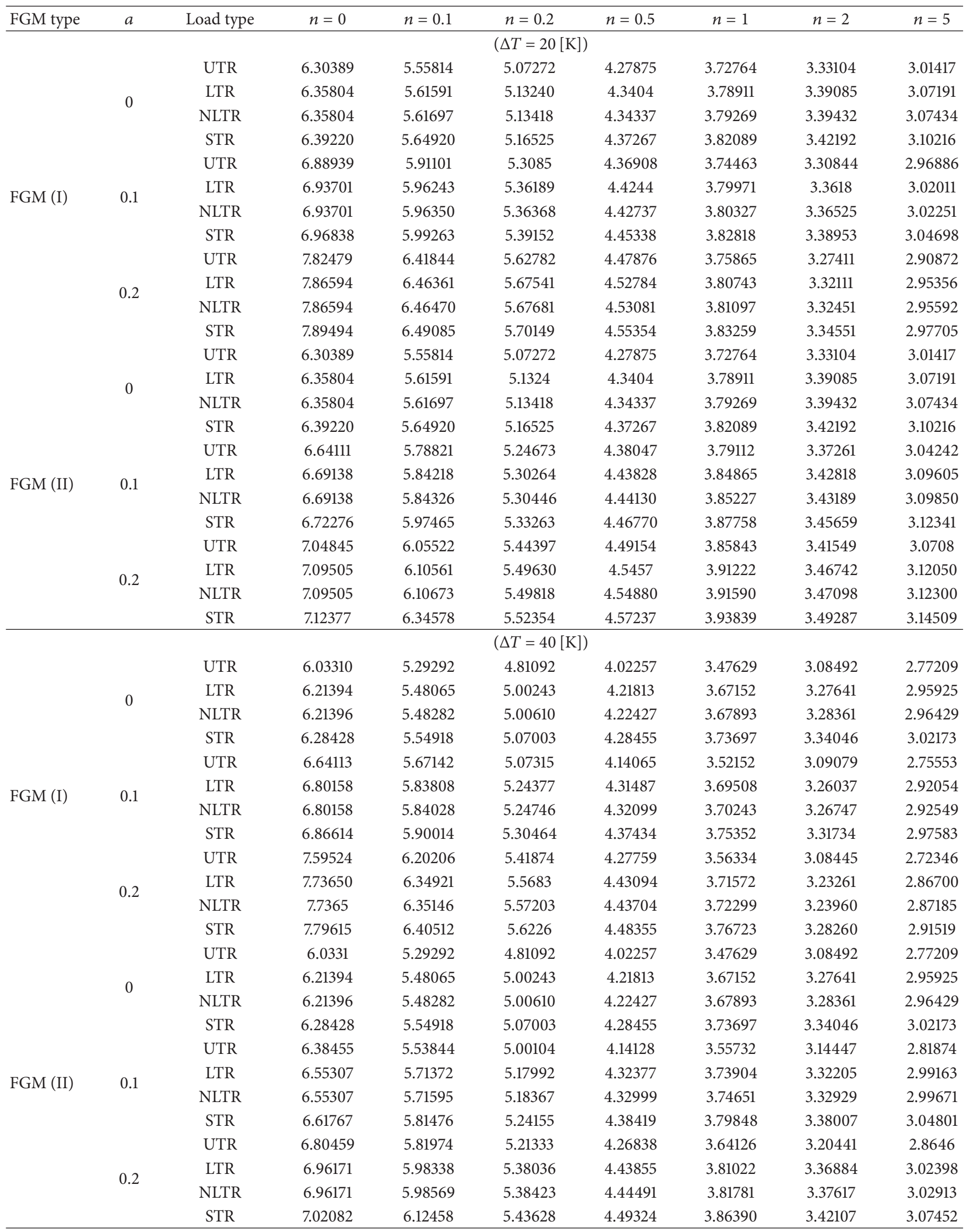


TABLE 3: Continued.

\begin{tabular}{|c|c|c|c|c|c|c|c|c|c|}
\hline FGM type & $a$ & Load type & $n=0$ & $n=0.1$ & $n=0.2$ & $n=0.5$ & $n=1$ & $n=2$ & $n=5$ \\
\hline & \multicolumn{9}{|c|}{$(\Delta T=80[\mathrm{~K}])$} \\
\hline \multirow{11}{*}{ FGM (I) } & \multirow{4}{*}{0} & UTR & 5.43496 & 4.70068 & 4.2211 & 3.43413 & 2.88836 & 2.49999 & 2.18730 \\
\hline & & LTR & 5.90834 & 5.193784 & 4.72667 & 3.95840 & 3.42142 & 3.03282 & 2.71915 \\
\hline & & NLTR & 5.90834 & 5.19842 & 4.73454 & 3.97159 & 3.43739 & 3.04839 & 2.73012 \\
\hline & & STR & 6.0582 & 5.33956 & 4.87041 & 4.09972 & 3.56096 & 3.16977 & 2.85332 \\
\hline & \multirow{4}{*}{0.1} & UTR & 6.10107 & 5.14332 & 4.55118 & 3.62453 & 3.00865 & 2.58294 & 2.25038 \\
\hline & & LTR & 6.51530 & 5.19378 & 4.99411 & 4.08325 & 3.47372 & 3.04569 & 2.70968 \\
\hline & & NLTR & 6.51530 & 5.57993 & 5.00197 & 4.09628 & 3.48941 & 3.06092 & 2.72034 \\
\hline & & STR & 6.65232 & 5.70667 & 5.12286 & 4.20898 & 3059742 & 3.16660 & 2.82749 \\
\hline & \multirow{4}{*}{0.2} & UTR & 7.10358 & 5.73356 & 4.95971 & 3.83009 & 3.12151 & 2.64928 & 2.29333 \\
\hline & & LTR & 7.46336 & 6.10799 & 5.34342 & 4.22684 & 3.52258 & 3.04631 & 2.68480 \\
\hline & & NLTR & 7.46336 & 6.11276 & 5.35131 & 4.23973 & 3.53799 & 3.06119 & 2.69516 \\
\hline \multirow{13}{*}{ FGM (II) } & & STR & 7.58973 & 6.22605 & 5.45779 & 4.33741 & 3.63088 & 3.15163 & 2.78670 \\
\hline & \multirow{4}{*}{0} & UTR & 5.43496 & 4.70068 & 4.2211 & 3.43413 & 2.88836 & 2.49999 & 2.18730 \\
\hline & & LTR & 5.90834 & 5.193784 & 4.72667 & 3.95840 & 3.42142 & 3.03282 & 2.71915 \\
\hline & & NLTR & 5.90834 & 5.19842 & 4.73454 & 3.97159 & 3.43739 & 3.04839 & 2.73012 \\
\hline & & STR & 6.0582 & 5.33956 & 4.87041 & 4.09972 & 3.56096 & 3.16977 & 2.85332 \\
\hline & \multirow{4}{*}{0.1} & UTR & 5.82315 & 4.98619 & 4.45317 & 3.59813 & 3.01746 & 2.61003 & 2.28715 \\
\hline & & LTR & 6.26055 & 5.44199 & 4.92030 & 4.08135 & 3.50684 & 3.09673 & 2.77022 \\
\hline & & NLTR & 6.26055 & 5.44675 & 4.92831 & 4.09464 & 3.52284 & 3.11228 & 2.78118 \\
\hline & & STR & 6.39781 & 5.59874 & 5.05092 & 4.20937 & 3.63293 & 3.22008 & 2.89057 \\
\hline & \multirow{4}{*}{0.2} & UTR & 6.27567 & 5.30382 & 4.70389 & 3.76693 & 3.14561 & 2.71632 & 2.38167 \\
\hline & & LTR & 6.68027 & 5.72544 & 5.13573 & 4.21244 & 3.59493 & 3.16080 & 2.82025 \\
\hline & & NLTR & 6.68027 & 5.73036 & 4.14395 & 4.22595 & 3.61109 & 3.17644 & 2.83130 \\
\hline & & STR & 6.80568 & 5.64570 & 5.25388 & 4.32784 & 3.70829 & 3.27130 & 2.92754 \\
\hline
\end{tabular}

FG beams, and this situation is more eminent for smaller power index parameter. Also, it is concluded that, for constant values of temperature changes, when the percentage of the metal is higher than ceramic $(1 \prec n)$, increasing volume fraction of porosity yields decrease in the nondimensional frequencies. However, this trend is opposite to increasing the temperature changes. Comparing the frequency values for FGM beams with even and uneven porosity distribution show that when the power index is in the range of [00.5 ], natural frequencies of the even porosity are higher than uneven ones. However, this behavior is opposite in the range of power-law index beyond 0.5 . In addition, for a certain value of temperature change and gradient index, changes in the porosity parameter $(a)$ lead to more variations in frequencies of even distribution in comparison with uneven one. In other words, in FGM-I, the porosity has more significant impact on natural frequency of beam than that of FGM-II.

Table 4 presents the effect of various temperature changes, porosity parameters, material graduations on the natural frequencies of the simply porous FG beams under uniform temperature rise with both porosity distributions. Here, again, it is seen that, by increasing the material powerlaw index, the nondimensional frequencies decrease. This is due to the increment in flexibility of the FG beams, since the percentage of metal phase increases when power index rises. Also, increasing the temperature changes yields decrease in the frequency parameters and it can be stated that these parameter have a notable effect on the fundamental frequency. By studying the result of Table 4 , it can be seen that the variations of frequencies depend on both temperature change and volume fraction index. For example, when $0 \prec$ $n \prec 1$ (beams with more percentage of ceramic), increasing of volume fraction of porosity leads to increment of fundamental frequency for all of temperature changes and porosity distributions, while, at even distribution, the trend of fundamental frequency changes is different for $1 \prec n$ (beams with more percentage of metal). For example, increasing volume fraction of porosity yields decrease in the nondimensional frequencies. However, this trend is opposite to increasing the temperature changes. When the temperature changes increase, the fundamental frequency changes. It is evident that, at uneven distribution of porosity, increasing of porosity parameters yields increasing nondimensional frequencies for all of temperature changes and power-law indexes.

Variations of the first nondimensional natural frequencies of the simply supported FG porous beams subjected to uniform temperature rising for different values of porosity and gradient index parameters are plotted in Figure 2. It is seen that the dimensionless frequencies of FG beam decrease with the increase of temperature change until they reach near zero (at the critical temperature point). This is due to the reduction in total stiffness of the beam, since geometrical stiffness decreases when temperature rises. One important observation within the range of temperature before the 
TABLE 4: Temperature and material graduation effect on first dimensionless natural frequency of S-S FG porous beam with different temperature changes and porosity parameter under uniform temperature rise $(L / h=20)$.

\begin{tabular}{|c|c|c|c|c|c|c|c|c|}
\hline FGM type & $a$ & $\Delta T=0$ & $\Delta T=20$ & $\Delta T=40$ & $\Delta T=80$ & $\Delta T=100$ & $\Delta T=120$ & $\Delta T=140$ \\
\hline & & & & & $n=0$ & & & \\
\hline \multirow{4}{*}{ FGM-I } & 0 & 6.55957 & 6.30389 & 6.03310 & 5.43496 & 5.09981 & 4.73303 & 4.32582 \\
\hline & 0.1 & 7.12576 & 6.88939 & 6.64113 & 6.10107 & 5.80417 & 5.48474 & 5.13790 \\
\hline & 0.2 & 8.04528 & 7.82479 & 7.59524 & 7.10358 & 6.83815 & 6.55684 & 6.25690 \\
\hline & 0 & 6.55957 & 6.30389 & 6.03310 & 5.43496 & 5.09981 & 4.73303 & 4.32582 \\
\hline \multirow[t]{4}{*}{ FGM-II } & 0.1 & 6.88457 & 6.64111 & 6.38455 & 5.82315 & 5.51229 & 5.17575 & 4.80744 \\
\hline & 0.2 & 7.28099 & 7.04845 & 6.80459 & 6.27567 & 5.98594 & 5.67521 & 5.39915 \\
\hline & & & & & $=0.5$ & & & \\
\hline & 0 & 4.51585 & 4.27875 & 4.02257 & 3.43413 & 3.08651 & 2.68466 & 2.19832 \\
\hline \multirow[t]{3}{*}{ FGM-I } & 0.1 & 4.58213 & 4.36908 & 4.14065 & 3.62453 & 3.32690 & 2.99204 & 2.60510 \\
\hline & 0.2 & 4.66783 & 4.47876 & 4.27759 & 3.83009 & 3.57746 & 3.29930 & 2.98806 \\
\hline & 0 & 4.51585 & 4.27875 & 4.02257 & 3.43413 & 3.08651 & 2.68466 & 2.19832 \\
\hline \multirow[t]{4}{*}{ FGM-II } & 0.1 & 4.60304 & 4.38047 & 4.14128 & 3.59813 & 3.28268 & 2.92503 & 2.50660 \\
\hline & 0.2 & 4.70024 & 4.49154 & 4.26838 & 3.76693 & 3.47998 & 3.15974 & 2.79427 \\
\hline & & & & & $n=1$ & & & \\
\hline & 0 & 3.95829 & 3.72764 & 3.47629 & 2.88836 & 2.53136 & 2.10424 & 1.54940 \\
\hline \multirow[t]{3}{*}{ FGM-I } & 0.1 & 3.95091 & 3.74463 & 3.52152 & 3.00865 & 2.70569 & 2.35577 & 1.93306 \\
\hline & 0.2 & 3.94056 & 3.75865 & 3.56334 & 3.12151 & 2.86664 & 2.58004 & 2.24928 \\
\hline & 0 & 3.95829 & 3.72764 & 3.47629 & 2.88836 & 2.53136 & 2.10424 & 1.54940 \\
\hline \multirow[t]{4}{*}{ FGM-II } & 0.1 & 4.00686 & 3.79112 & 3.55732 & 3.01746 & 2.69634 & 2.32229 & 1.86318 \\
\hline & 0.2 & 4.05989 & 3.85843 & 3.64126 & 3.14561 & 2.85597 & 2.52554 & 2.13508 \\
\hline & & & & & $n=2$ & & & \\
\hline & 0 & 3.55529 & 3.33104 & 3.08492 & 2.49999 & 2.13545 & 1.68262 & 1.03051 \\
\hline \multirow[t]{3}{*}{ FGM-I } & 0.1 & 3.50825 & 3.30844 & 3.09073 & 2.58294 & 2.27626 & 1.91230 & 1.44817 \\
\hline & 0.2 & 3.44947 & 3.27411 & 3.08445 & 2.64928 & 2.39337 & 2.09961 & 1.74880 \\
\hline & 0 & 3.55529 & 3.33104 & 3.08492 & 2.49999 & 2.13545 & 1.68262 & 1.03051 \\
\hline \multirow[t]{4}{*}{ FGM-II } & 0.1 & 3.58170 & 3.37261 & 3.14447 & 2.61003 & 2.28511 & 1.89595 & 1.38920 \\
\hline & 0.2 & 3.61002 & 3.41549 & 3.20441 & 2.71632 & 2.42572 & 2.08703 & 1.67099 \\
\hline & & & & & $n=5$ & & & \\
\hline & 0 & 3.23323 & 3.01417 & 2.77209 & 2.18730 & 1.81215 & 1.32261 & 0.42425 \\
\hline \multirow[t]{3}{*}{ FGM-I } & 0.1 & 3.16336 & 2.96886 & 2.75553 & 2.25038 & 1.93806 & 1.55511 & 1.02507 \\
\hline & 0.2 & 3.07867 & 2.90872 & 2.72367 & 2.29333 & 2.03530 & 1.73218 & 1.35400 \\
\hline & 0 & 3.23323 & 3.01417 & 2.77209 & 2.18730 & 1.81215 & 1.32261 & 0.42425 \\
\hline \multirow[t]{2}{*}{ FGM-II } & 0.1 & 3.24609 & 3.04242 & 2.81874 & 2.28715 & 1.95630 & 1.54641 & 0.96094 \\
\hline & 0.2 & 3.25967 & 3.07080 & 2.86460 & 2.38167 & 2.08853 & 1.73843 & 1.28550 \\
\hline
\end{tabular}

critical temperature is that the porous FG beams with higher value of porosity volume fraction usually provide larger values of the frequency results. However, this behavior is opposite in the range of temperature beyond the critical temperature. Also, it is seen that temperature change has a softening effect on FG beam at prebuckling region and a rise in temperature increases this effect. It is also observable that the branching point of the FG beam is postponed by consideration of the lower porosity parameter due to the fact that the lower porosity indexes result in the decrease of stiffness of the structure. In addition, it can be emphasizing that the buckling temperatures decrease depending on an increment in material property gradient index and porosity parameter.
In order to clearly understand the difference between different temperature risings, Figure 3 displays the variations of the first nondimensional natural frequencies of S-S FG porous beams subjected to four cases of thermal loading (UTR, LTR, NLTR, and STR) for different porosity volume fraction and constant power exponent and slenderness ratio $(L / h=50, n=1)$. A comparison between these figures show that the difference of variant porosity volume fractions is more considerable under sinusoidal temperature rise. It can be found that critical temperature point of FG beams with respect to sinusoidal temperature rises is higher than the other temperature risings.

Comparisons of the first dimensionless natural frequencies of S-S FG (I) beam subjected to NLTR with change of porosity volume fraction and power exponent are presented 


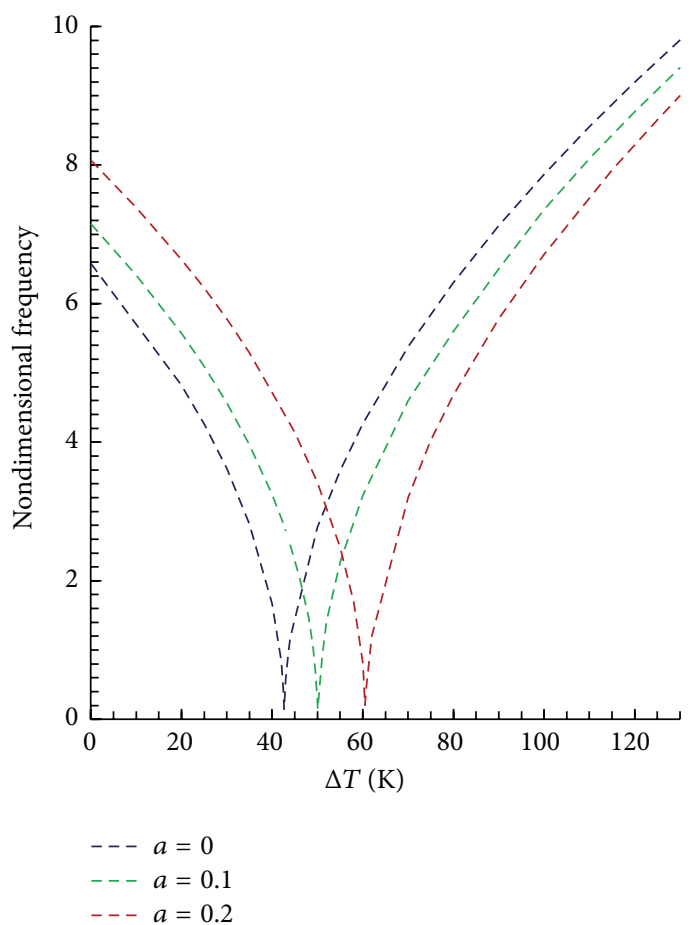

(a) $n=0$

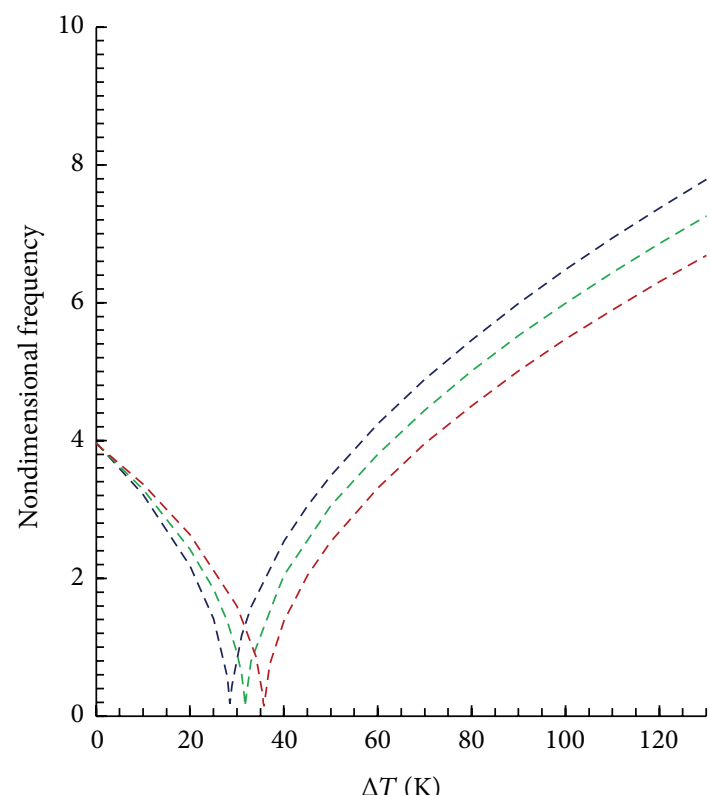

$$
\begin{aligned}
& --a=0 \\
& --a=0.1 \\
& --a=0.2
\end{aligned}
$$

(c) $n=1$

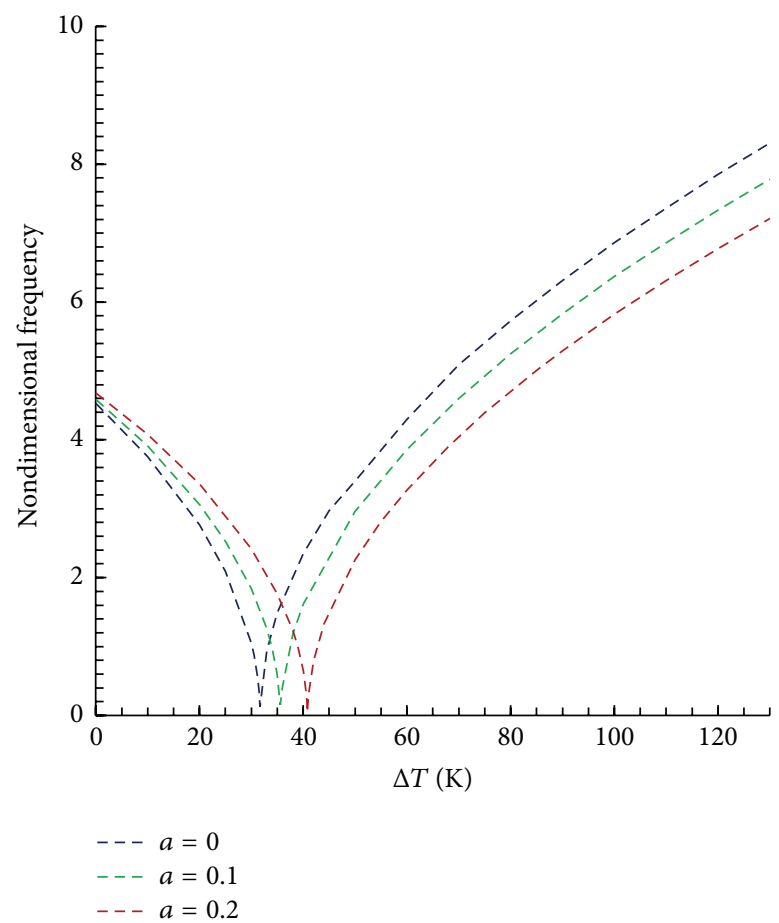

(b) $n=0.5$

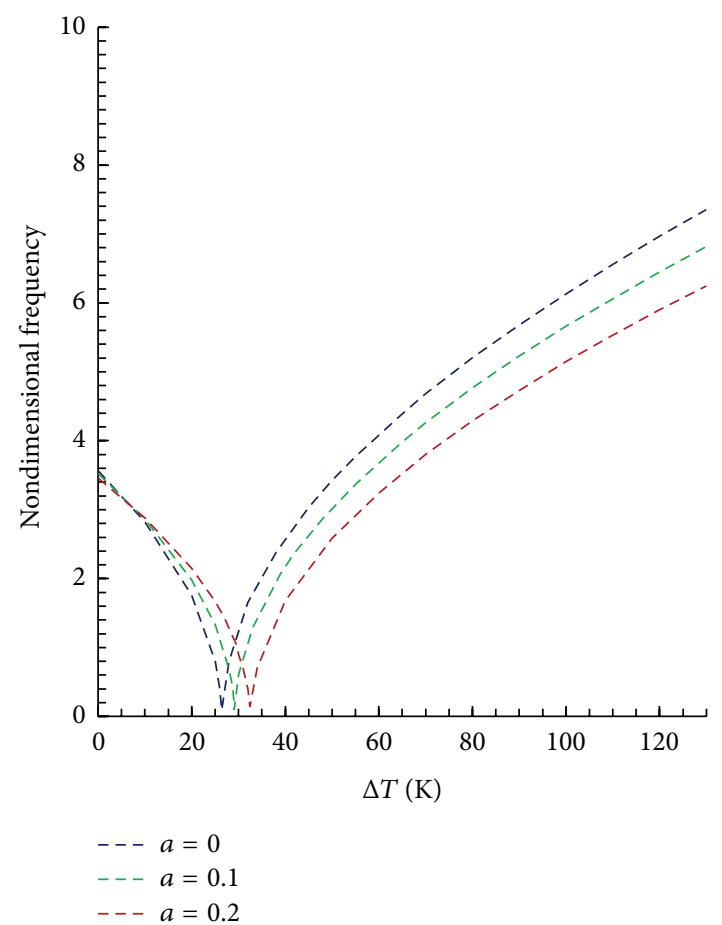

(d) $n=2$

FIGURE 2: Comparison of the nondimensional natural frequency of the S-S porous FG beam with respect to UTR for different values of power exponents and porosity parameter $(L / h=50, n=1)$.

in Figure 4 at constant slenderness ratio $(L / h=20)$. Four types of temperature change are considered as $0,20,40$, and 80. It is observed from the results of Figure 4 that the dimensionless natural frequencies of porous FG beam decrease with the increase of power indexes. When the power exponent is in the range of 0 to 2 , the nondimensional frequencies reduce with high rate compared to those when the power exponent is in the range between 2 and 10. Also, the effect of temperature change is obvious, the nondimensional natural frequencies will be decreased by increasing of temperature change for all gradient indexes, and thus various temperature rises have a significant effect on the fundamental 


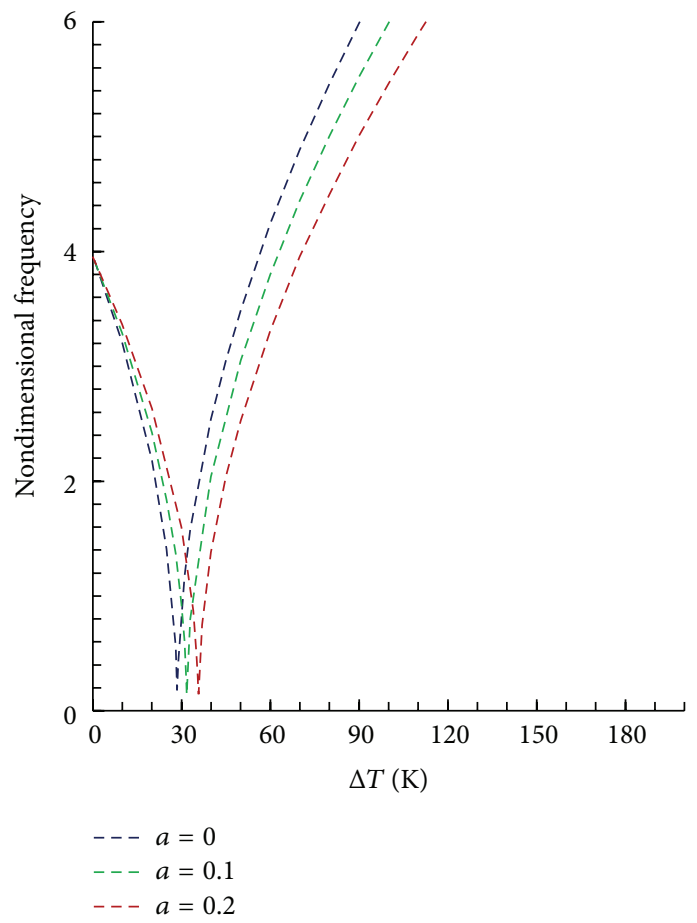

(a) UTR

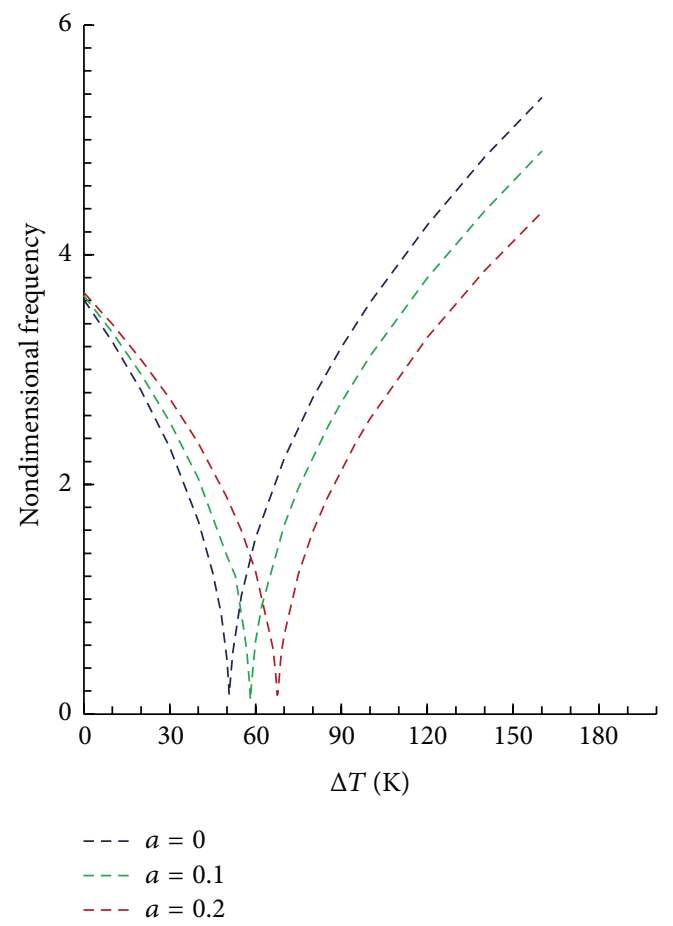

(c) NLTR

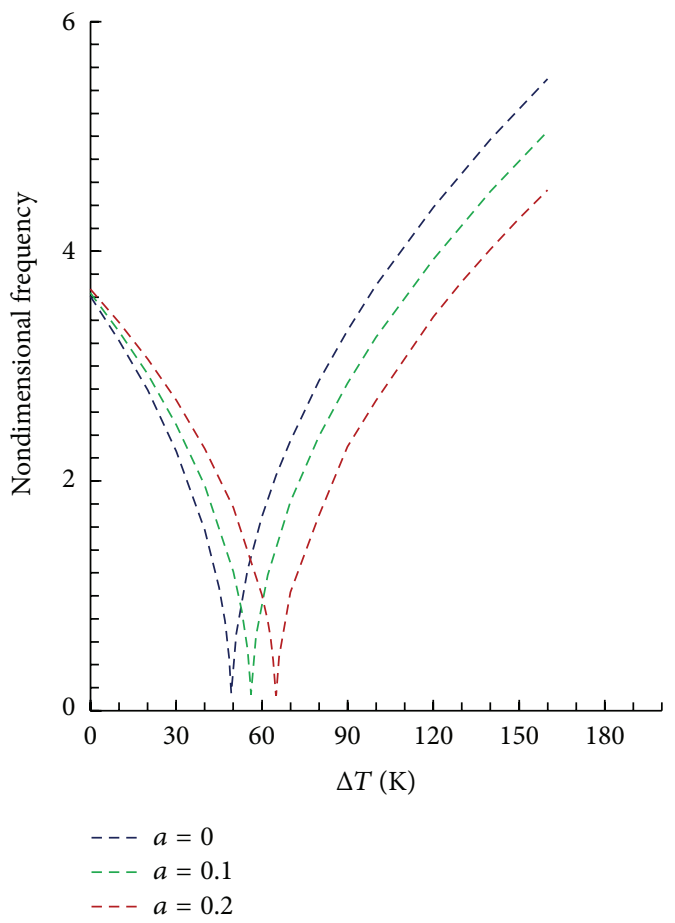

(b) LTR

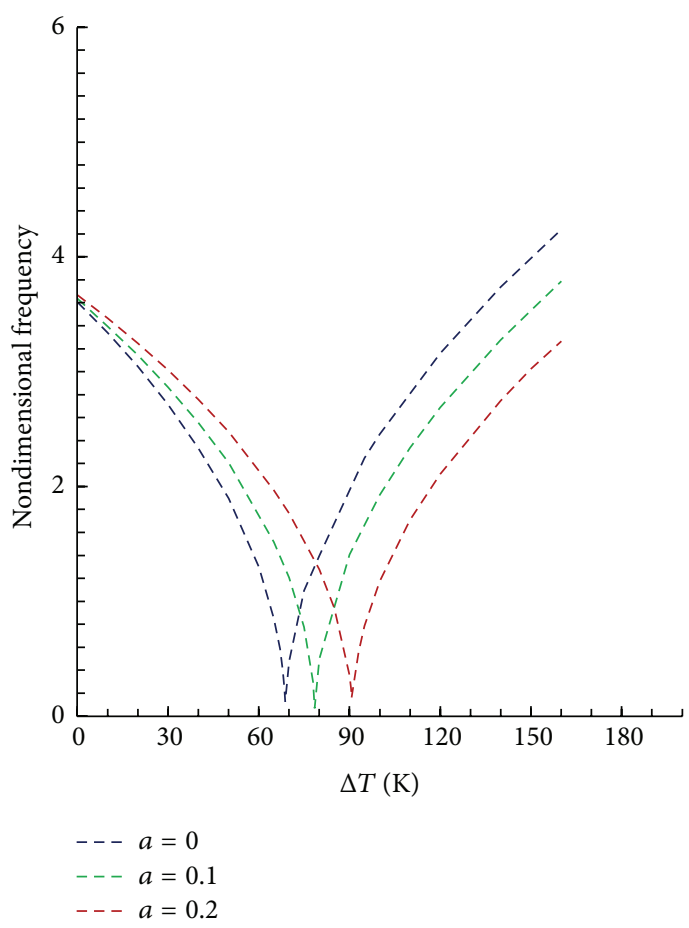

(d) STR

FIGURE 3: Comparison of the nondimensional natural frequency of the S-S porous FG beam with respect to various temperature risings for different values porosity $(L / h=50, n=1)$.

frequency of the porous FG beam. Also, it is concluded that porosity effect in even distributions depends on power indexes and temperature changes. For example, at constant value of temperature changes, by increasing the porosity parameters, the natural frequencies first increase; however, this behavior is opposite to a certain value of the power indexes. In other words, at a constant value of temperature changes from a certain value of power indexes, increasing of porosity leads to decreasing of nondimensional frequencies. By comparing Figures $4(\mathrm{a})-4(\mathrm{~d})$, it is concluded that this 


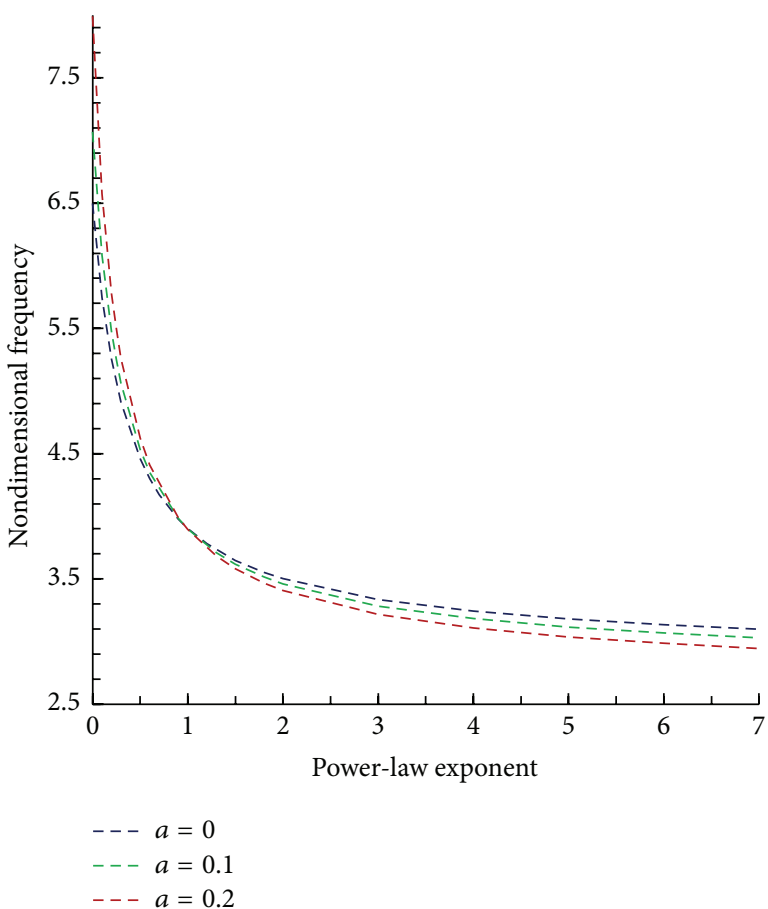

(a) $\Delta T=0$

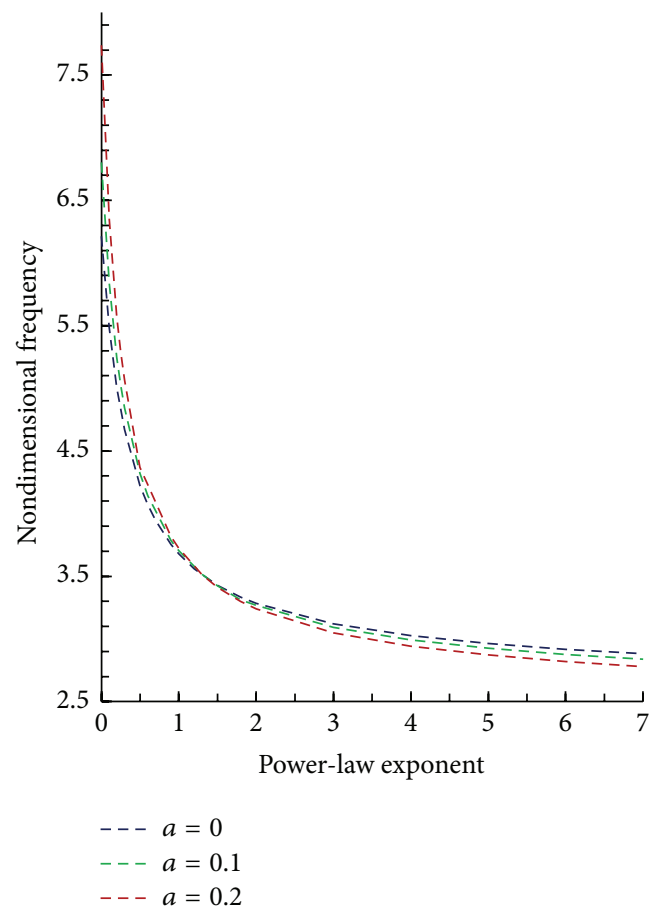

(c) $\Delta T=40$

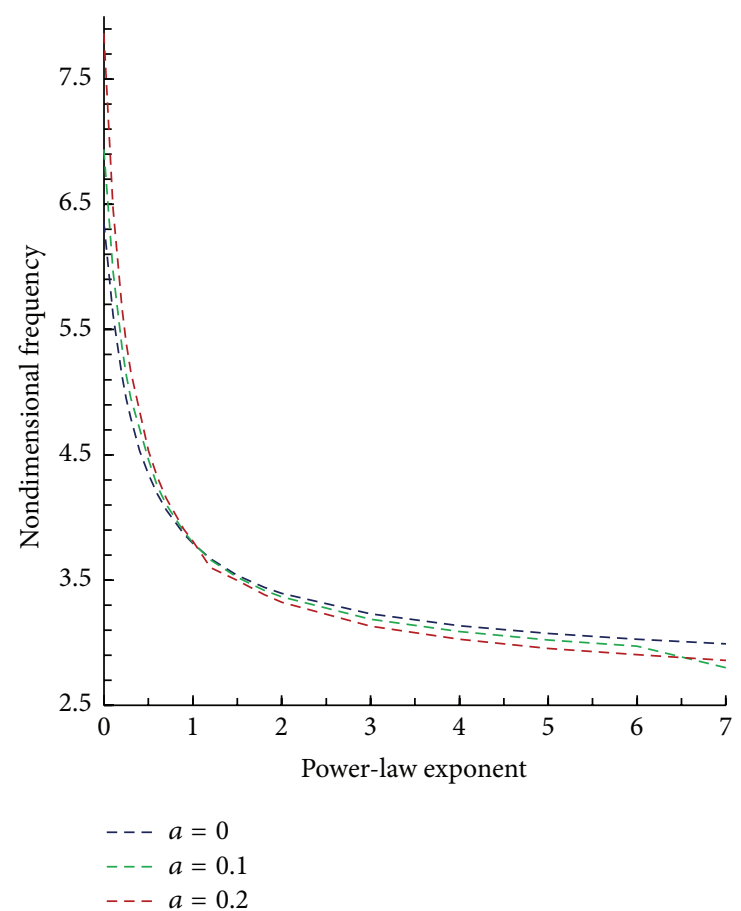

(b) $\Delta T=20$

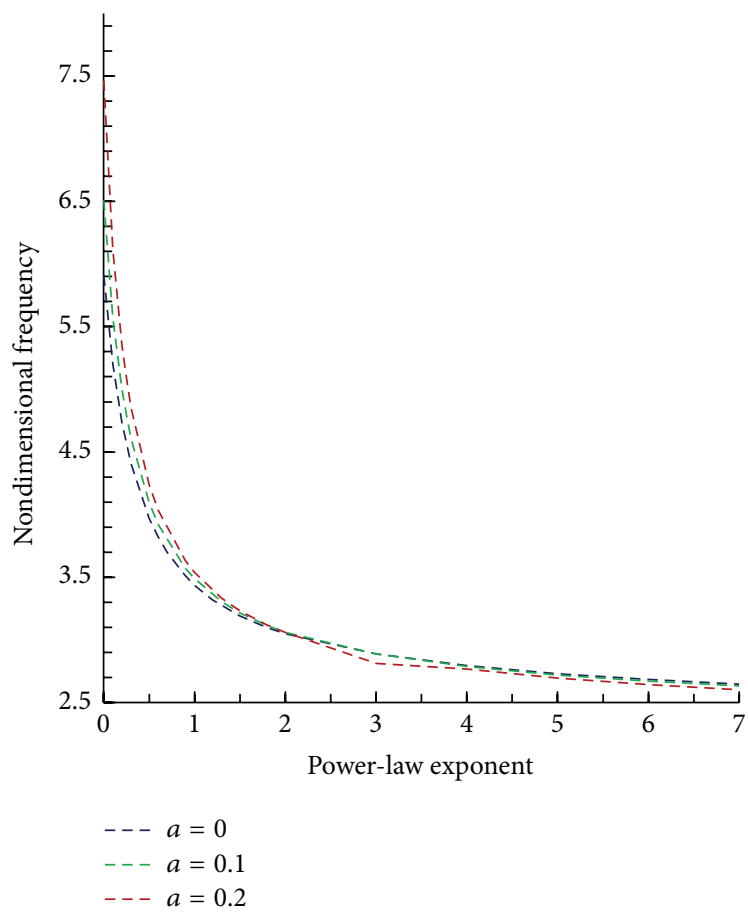

(d) $\Delta T=80$

FIGURE 4: The variation of the first dimensionless frequency of S-S FGM (I) beam with material graduation and porosity for nonlinear temperature rises $(L / h=20)$.

behavior is dependent on temperature changes. By increasing of temperature changes, the certain value of the $n$ has gone up.

Comparisons of the first dimensionless natural frequencies of S-S FG (II) beam subjected to STR with change of porosity volume fraction and power exponent are presented in Figure 5 at constant slenderness ratio $(L / h=20)$. From the results of Figure 5, it is observed that increasing the porosity volume fraction yields increasing nondimensional frequency of FG beams with uneven porosity distribution for every power-law exponent and temperature change. 


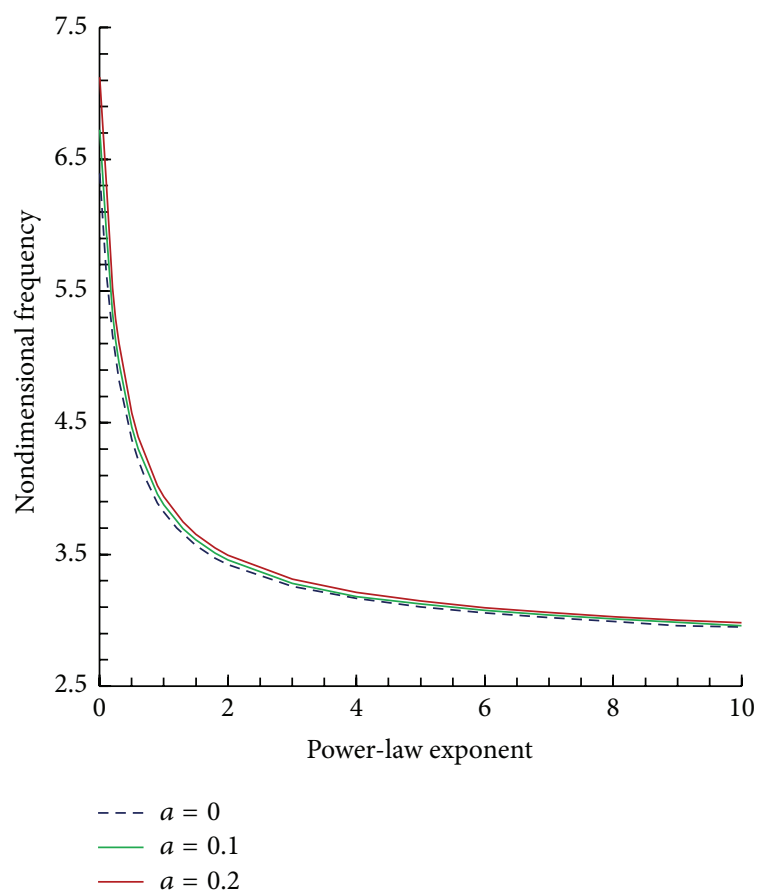

(a) $\Delta T=0$

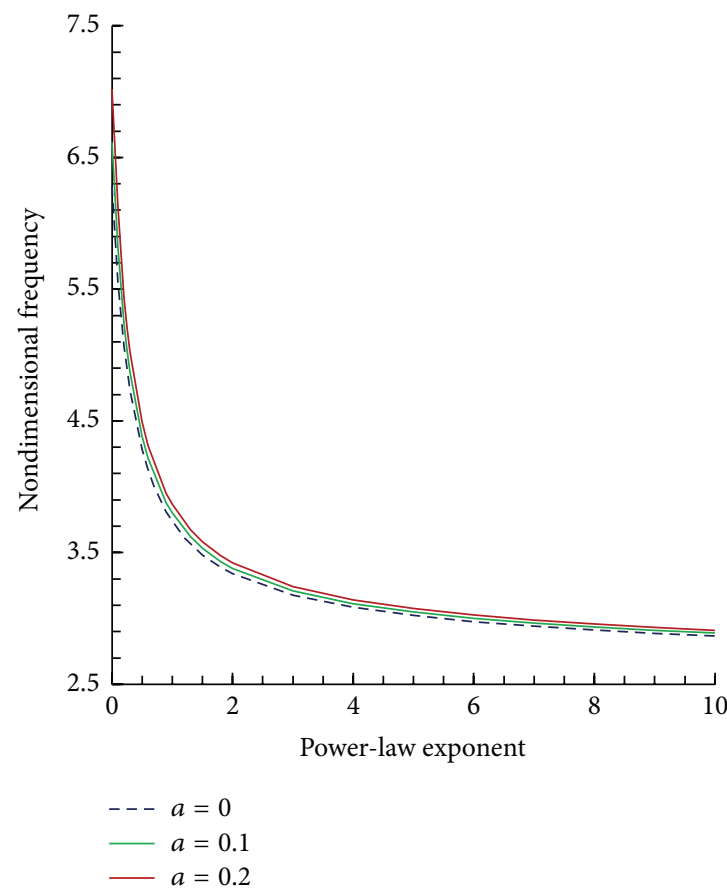

(c) $\Delta T=40$

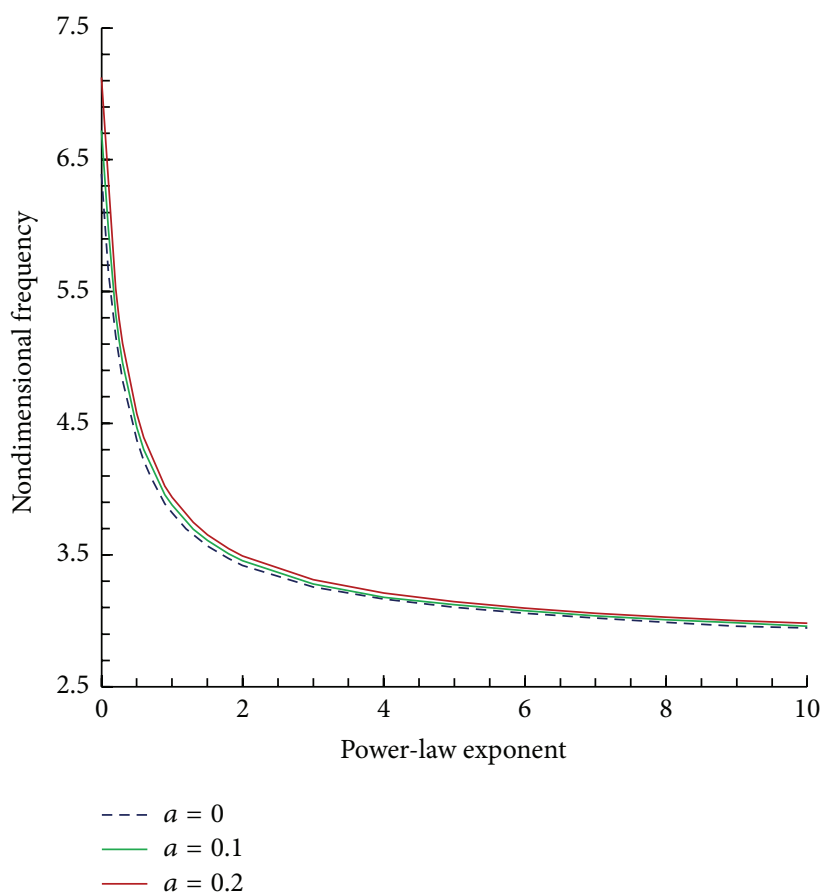

(b) $\Delta T=20$

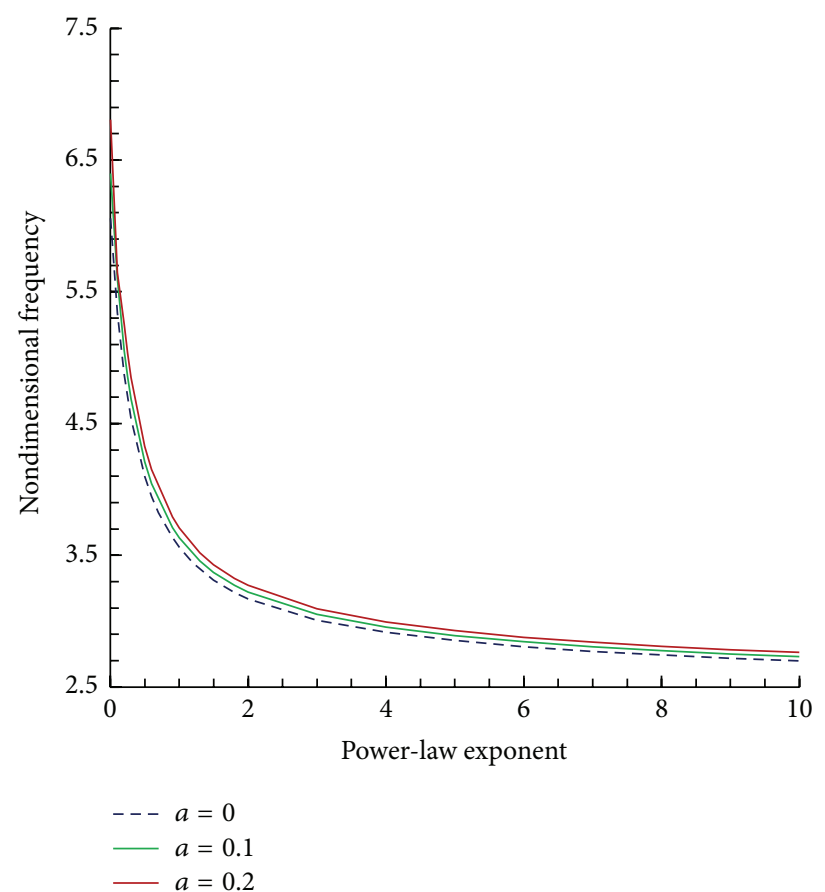

(d) $\Delta T=80$

FIGURE 5: The variation of the first dimensionless frequency of S-S FGM (II) beam with material graduation and porosity for different sinusoidal temperature rises $(L / h=20)$.

The natural frequency parameter as a function of power law indexes for sinusoidal temperature rises and different porosity parameters are presented in Figure 6 (for FGM (I) subjected to STR with S-S boundary condition). Different porosity parameter has been considered as $a=0, a=0.1$, $a=0.2$. It is easily deduced that an increase in temperature change gives rise to decrease in the first dimensionless natural frequency for all gradient indexes.

Comparisons of the first nondimensional natural frequencies of S-S FG (I) beam subjected to both cases of thermal loading (UTR and STR) with change of porosity volume fractions and power exponents at constant slenderness 


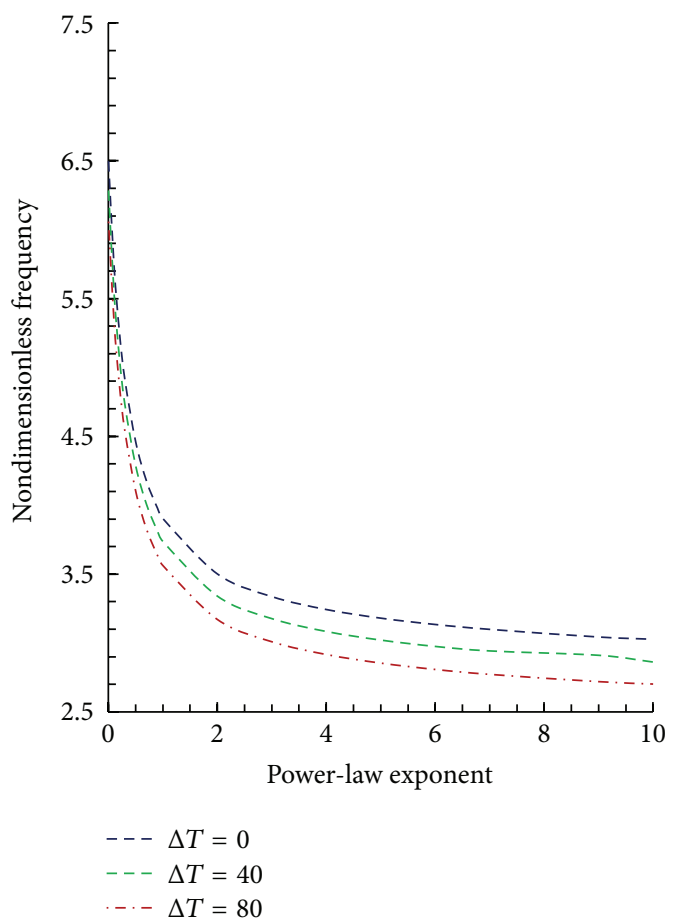

(a) $a=0$

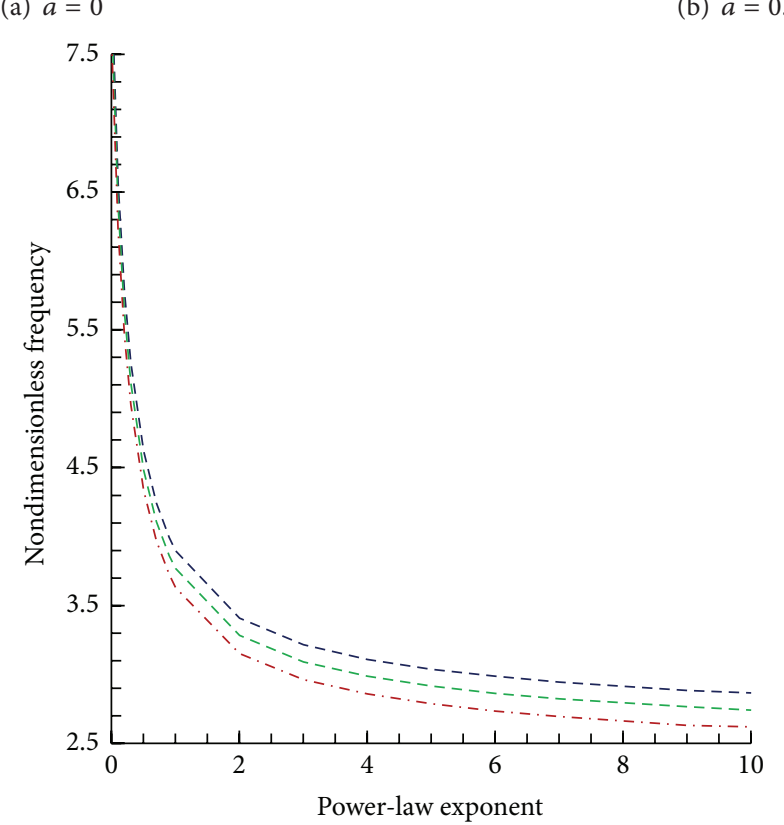

(b) $a=0.1$

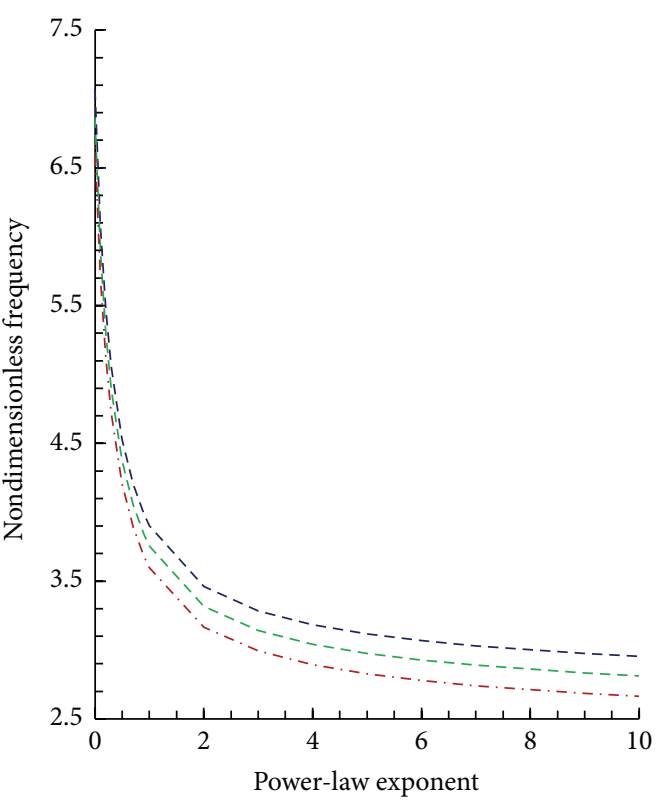

$--\Delta T=0$

- - $\Delta T=40$

-. $\Delta T=80$ 


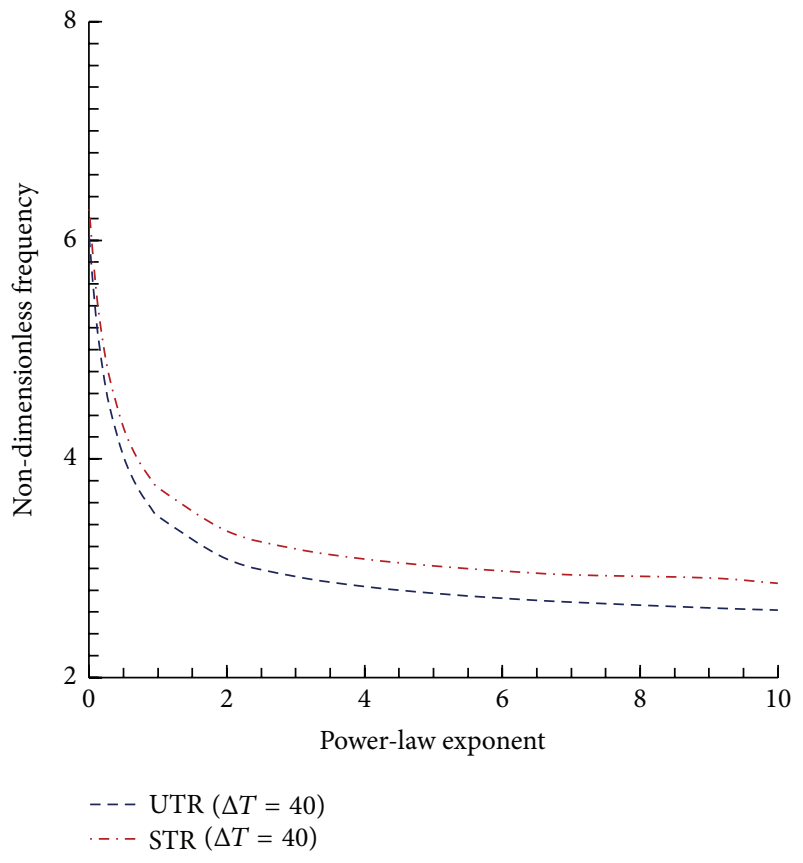

(a) $a=0$

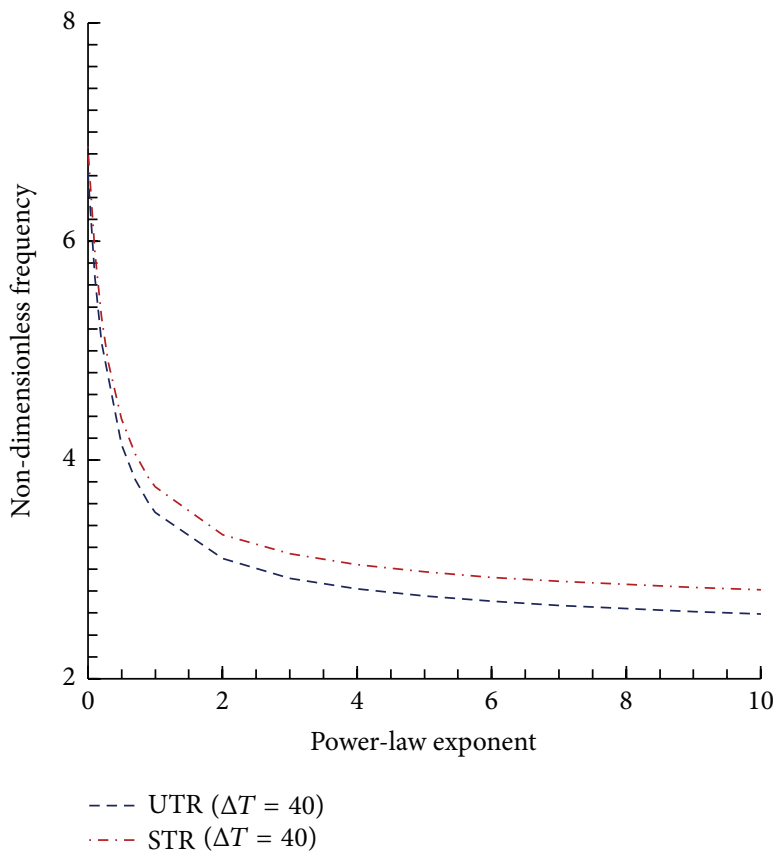

(b) $a=0.1$

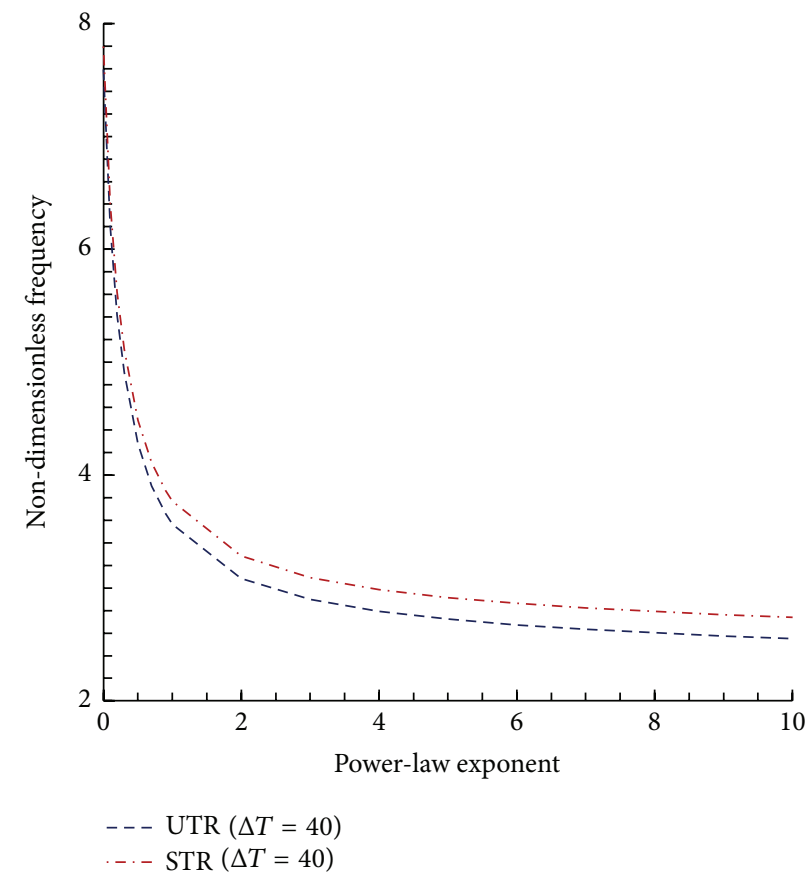

(c) $a=0.2$

Figure 7: Comparison of the first dimensionless frequency of S-S FG (I) beam with material graduation and uniform and sinusoidal temperature rises for different porosities $(\Delta T=40, L / h=20)$.

\section{Conclusions}

In this research, thermomechanical vibrational characteristic of the temperature-dependent FG porous beams subjected to various thermal loading with two porosity distributions is presented. The equations of motion are derived based on third-order shear deformation beam theory and simply boundary condition is considered. Material's properties are temperature-dependent and also vary in the thickness direction based on modified rule of mixture. The governing differential equations are derived within the framework of higher-order shear deformation beam theory and by using Hamilton's principle. The Navier-based analytical model is used to solve governing partial differential equations. According to the numerical results, it is revealed that the proposed modeling can provide accurate frequency results of the FG beams as compared to the other solution results and some cases in the literature. As a result, the characteristics of 
vibration for FGM porous beams are significantly influenced by temperature field, volume fraction of porosity, powerlaw indexes, and porosity distributions. The effects of the induced thermal environment, volume fraction of porosity, material property gradient index, and porosity distribution on fundamental frequencies of porous FG beams are investigated. Numerical results show the following:

(i) By increasing the gradient index value, the nondimensional frequencies are found to decrease.

(ii) Fundamental frequencies decrease by increasing the four temperature risings and all two porosity distributions.

(iii) The responses of the nondimensional frequencies in the FG porous beams according to geometric parameters, under sinusoidal temperature rise, are very similar to those under nonlinear, linear, and uniform temperature rise. However, the critical temperature gradient under sinusoidal temperature rise is higher than those under the other temperature rises.

(iv) The nondimensional frequency predicted by STR is always greater than those UTR, LTR, and NLTR and the uniform temperature rise has more significant effect on the nondimensional frequencies than the other temperature rises.

(v) For FGM-I, at a constant value of temperature change, increasing the volume fraction of porosity first yields the increase in fundamental frequencies; however, this trend is vice versa for upper values of gradient indexes. This behavior is dependent on power-law indexes and temperature changes. And for FGM-II, increasing the volume fraction of porosity yields the increase in fundamental frequencies for all values of gradient indexes and temperature changes.

(vi) In FGM-I, the porosity has more significant impact on natural frequencies of the beam in comparison with FGM-II.

It is concluded that various factors such as porosity parameter, porosity distribution, temperature rising, and power-law index have a notable effect on the nondimensional frequencies of FG beams with porosities, which emphasizes the importance of inspected porosity volume fraction effect in thermal environment. Therefore, the porosity and thermal effects should be considered in the analysis of vibration behavior of FG structures.

\section{Competing Interests}

The authors declare that they have no competing interests.

\section{References}

[1] M. Şimşek and T. Kocatürk, "Free and forced vibration of a functionally graded beam subjected to a concentrated moving harmonic load," Composite Structures, vol. 90, no. 4, pp. 465473, 2009.
[2] H.-T. Thai and T. P. Vo, "Bending and free vibration of functionally graded beams using various higher-order shear deformation beam theories," International Journal of Mechanical Sciences, vol. 62, no. 1, pp. 57-66, 2012.

[3] N. Wattanasakulpong, B. Gangadhara Prusty, D. W. Kelly, and M. Hoffman, "Free vibration analysis of layered functionally graded beams with experimental validation," Materials \& Design, vol. 36, pp. 182-190, 2012.

[4] D. K. Jha, T. Kant, and R. K. Singh, "A critical review of recent research on functionally graded plates," Composite Structures, vol. 96, pp. 833-849, 2013.

[5] F. Ebrahimi, M. H. Naei, and A. Rastgoo, "Geometrically nonlinear vibration analysis of piezoelectrically actuated FGM plate with an initial large deformation," Journal of Mechanical Science and Technology, vol. 23, no. 8, pp. 2107-2124, 2009.

[6] F. Ebrahimi, A. Rastgoo, and A. A. Atai, "A theoretical analysis of smart moderately thick shear deformable annular functionally graded plate," European Journal of Mechanics-A/Solids, vol. 28, no. 5, pp. 962-973, 2009.

[7] M. Aydogdu and V. Taskin, "Free vibration analysis of functionally graded beams with simply supported edges," Materials \& Design, vol. 28, no. 5, pp. 1651-1656, 2007.

[8] M. Şimşek, "Fundamental frequency analysis of functionally graded beams by using different higher-order beam theories," Nuclear Engineering and Design, vol. 240, no. 4, pp. 697-705, 2010.

[9] K. K. Pradhan and S. Chakraverty, "Free vibration of Euler and Timoshenko functionally graded beams by Rayleigh-Ritz method," Composites Part B: Engineering, vol. 51, pp. 175-184, 2013.

[10] H. J. Xiang and J. Yang, "Free and forced vibration of a laminated FGM Timoshenko beam of variable thickness under heat conduction," Composites Part B: Engineering, vol. 39, no. 2, pp. 292-303, 2008.

[11] A. Mahi, E. A. Adda Bedia, A. Tounsi, and I. Mechab, "An analytical method for temperature-dependent free vibration analysis of functionally graded beams with general boundary conditions," Composite Structures, vol. 92, no. 8, pp. 1877-1887, 2010.

[12] A. Fallah and M. M. Aghdam, “Thermo-mechanical buckling and nonlinear free vibration analysis of functionally graded beams on nonlinear elastic foundation," Composites Part B: Engineering, vol. 43, no. 3, pp. 1523-1530, 2012.

[13] D.-G. Zhang, “Thermal post-buckling and nonlinear vibration analysis of FGM beams based on physical neutral surface and high order shear deformation theory," Meccanica, vol. 49, no. 2, pp. 283-293, 2014.

[14] R. Rajendran, K. Prem Sai, B. Chandrasekar, A. Gokhale, and S. Basu, "Preliminary investigation of aluminium foam as an energy absorber for nuclear transportation cask," Materials \& Design, vol. 29, no. 9, pp. 1732-1739, 2008.

[15] K. A. Khor and Y. W. Gu, "Effects of residual stress on the performance of plasma sprayed functionally graded $\mathrm{ZrO}_{2} / \mathrm{NiCoCrAlY}$ coatings," Materials Science and Engineering $A$, vol. 277, no. 1-2, pp. 64-76, 2000.

[16] S. Seifried, M. Winterer, and H. Hahn, "Nanocrystalline gradient films through chemical vapor synthesis," Scripta Materialia, vol. 44, no. 8-9, pp. 2165-2168, 2001.

[17] Y. Watanabe, H. Eryu, and K. Matsuura, "Evaluation of threedimensional orientation of $\mathrm{Al}_{3} \mathrm{Ti}$ platelet in $\mathrm{Al}$-based functionally graded materials fabricated by a centrifugal casting technique," Acta Materialia, vol. 49, no. 5, pp. 775-783, 2001. 
[18] X. Peng, M. Yan, and W. Shi, "A new approach for the preparation of functionally graded materials via slip casting in a gradient magnetic field," Scripta Materialia, vol. 56, no. 10, pp. 907-909, 2007.

[19] C. Song, Z. Xu, and J. Li, "Structure of in situ Al/Si functionally graded materials by electromagnetic separation method," Materials \& Design, vol. 28, no. 3, pp. 1012-1015, 2007.

[20] J. Zhu, Z. Lai, Z. Yin, J. Jeon, and S. Lee, "Fabrication of $\mathrm{ZrO}_{2}-$ $\mathrm{NiCr}$ functionally graded material by powder metallurgy," Materials Chemistry and Physics, vol. 68, no. 1-3, pp. 130-135, 2001.

[21] E. Magnucka-Blandzi, "Dynamic stability of a metal foam circular plate," Journal of Theoretical and Applied Mechanics, vol. 47, no. 2, pp. 421-433, 2009.

[22] E. Magnucka-Blandzi, "Non-linear analysis of dynamic stability of metal foam circular plate," Journal of Theoretical and Applied Mechanics, vol. 48, no. 1, pp. 207-217, 2010.

[23] E. Magnucka-Blandzi, "Axi-symmetrical deflection and buckling of circular porous-cellular plate," Thin-Walled Structures, vol. 46, no. 3, pp. 333-337, 2008.

[24] S. A. Yahia, H. A. Atmane, M. S. Houari, and A. Tounsi, "Wave propagation in functionally graded plates with porosities using various higher-order shear deformation plate theories," Structural Engineering and Mechanics, vol. 53, no. 6, pp. 11431165, 2015.

[25] I. Mechab, B. Mechab, S. Benaissa, B. Serier, and B. Bachir Bouiadjra, "Free vibration analysis of FGM nanoplate with porosities resting on Winkler Pasternak elastic foundations based on two-variable refined plate theories," Journal of the Brazilian Society of Mechanical Sciences and Engineering, 2016.

[26] T. Belica and K. Magnucki, "Dynamic stability of a porous cylindrical shell subjected to impulse of forces combined," Journal of KONES, vol. 14, pp. 39-48, 2007.

[27] N. Wattanasakulpong and V. Ungbhakorn, "Linear and nonlinear vibration analysis of elastically restrained ends FGM beams with porosities," Aerospace Science and Technology, vol. 32, no. 1, pp. 111-120, 2014.

[28] F. Ebrahimi and M. Mokhtari, "Transverse vibration analysis of rotating porous beam with functionally graded microstructure using the differential transform method," Journal of the Brazilian Society of Mechanical Sciences and Engineering, vol. 37, no. 4, pp. 1435-1444, 2015.

[29] N. Wattanasakulpong and A. Chaikittiratana, "Flexural vibration of imperfect functionally graded beams based on Timoshenko beam theory: Chebyshev collocation method," Meccanica, vol. 50, no. 5, pp. 1331-1342, 2015.

[30] F. Ebrahimi and M. Zia, "Large amplitude nonlinear vibration analysis of functionally graded Timoshenko beams with porosities," Acta Astronautica, vol. 116, pp. 117-125, 2015.

[31] H. A. Atmane, A. Tounsi, and F. Bernard, "Effect of thickness stretching and porosity on mechanical response of a functionally graded beams resting on elastic foundations," International Journal of Mechanics and Materials in Design, pp. 1-4, 2015.

[32] F. Ebrahimi, F. Ghasemi, and E. Salari, "Investigating thermal effects on vibration behavior of temperature-dependent compositionally graded Euler beams with porosities," Meccanica, vol. 51, no. 1, pp. 223-249, 2016.

[33] M. Şimşek and J. N. Reddy, "Bending and vibration of functionally graded microbeams using a new higher order beam theory and the modified couple stress theory," International Journal of Engineering Science, vol. 64, pp. 37-53, 2013.
[34] J. N. Reddy, "A simple higher-order theory for laminated composite plates," Journal of Applied Mechanics, vol. 51, no. 4, pp. 745-752, 1984.

[35] Y. Yesilce and H. H. Catal, "Solution of free vibration equations of semi-rigid connected Reddy-Bickford beams resting on elastic soil using the differential transform method," Archive of Applied Mechanics, vol. 81, no. 2, pp. 199-213, 2011.

[36] Y. S. Touloukian, Thermophysical Properties of High Temperature Solid Materials. Volume 4. Oxides and Their Solutions and Mixtures. Part I. Simple Oxygen Compounds and Their Mixtures, DTIC Document, Defense Technical Information Center, 1966.

[37] F. Ebrahimi and M. R. Barati, "A nonlocal higher-order shear deformation beam theory for vibration analysis of sizedependent functionally graded nanobeams," Arabian Journal for Science and Engineering, 2015.

[38] Y. Kiani and M. R. Eslami, "An exact solution for thermal buckling of annular FGM plates on an elastic medium," Composites Part B: Engineering, vol. 45, no. 1, pp. 101-110, 2013.

[39] K.-S. Na and J.-H. Kim, "Three-dimensional thermal buckling analysis of functionally graded materials," Composites Part B: Engineering, vol. 35, no. 5, pp. 429-437, 2004. 


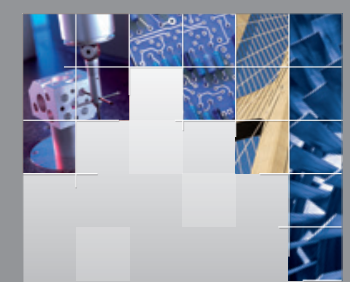

\section{Enfincering}
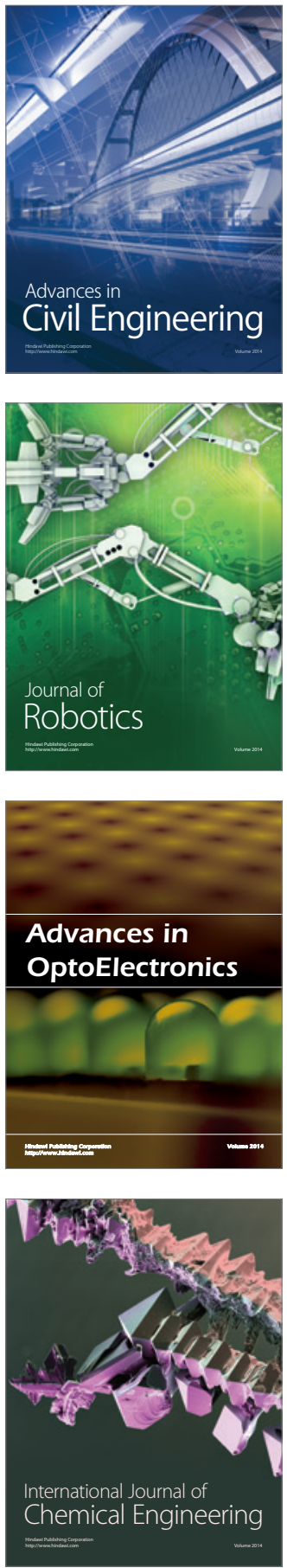

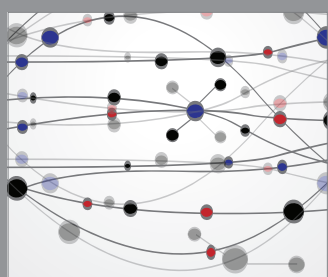

The Scientific World Journal

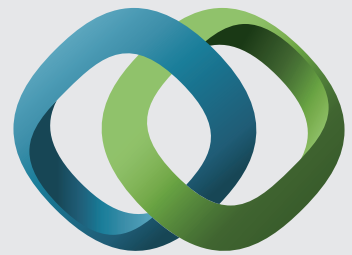

\section{Hindawi}

Submit your manuscripts at

http://www.hindawi.com
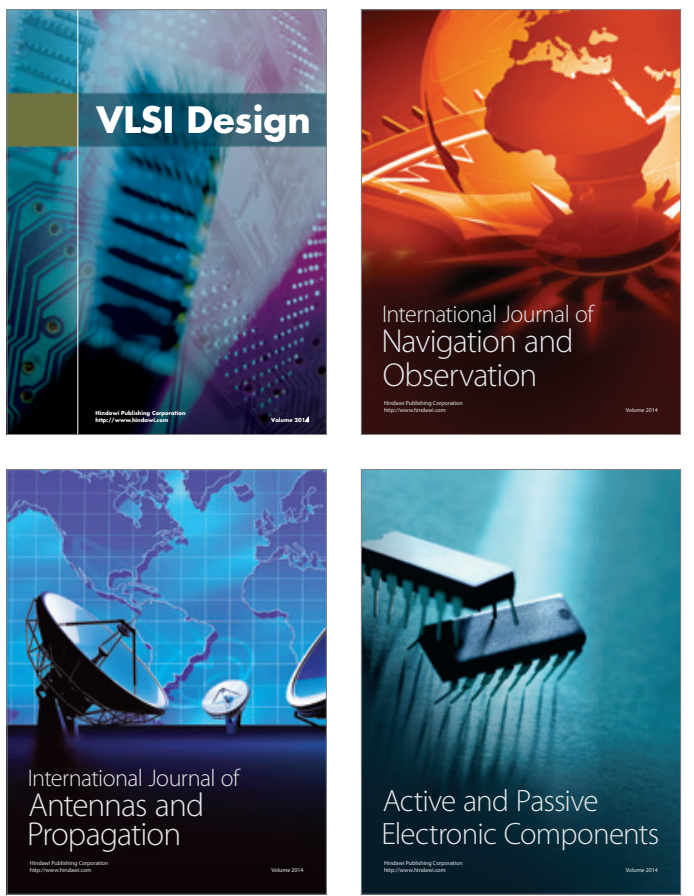
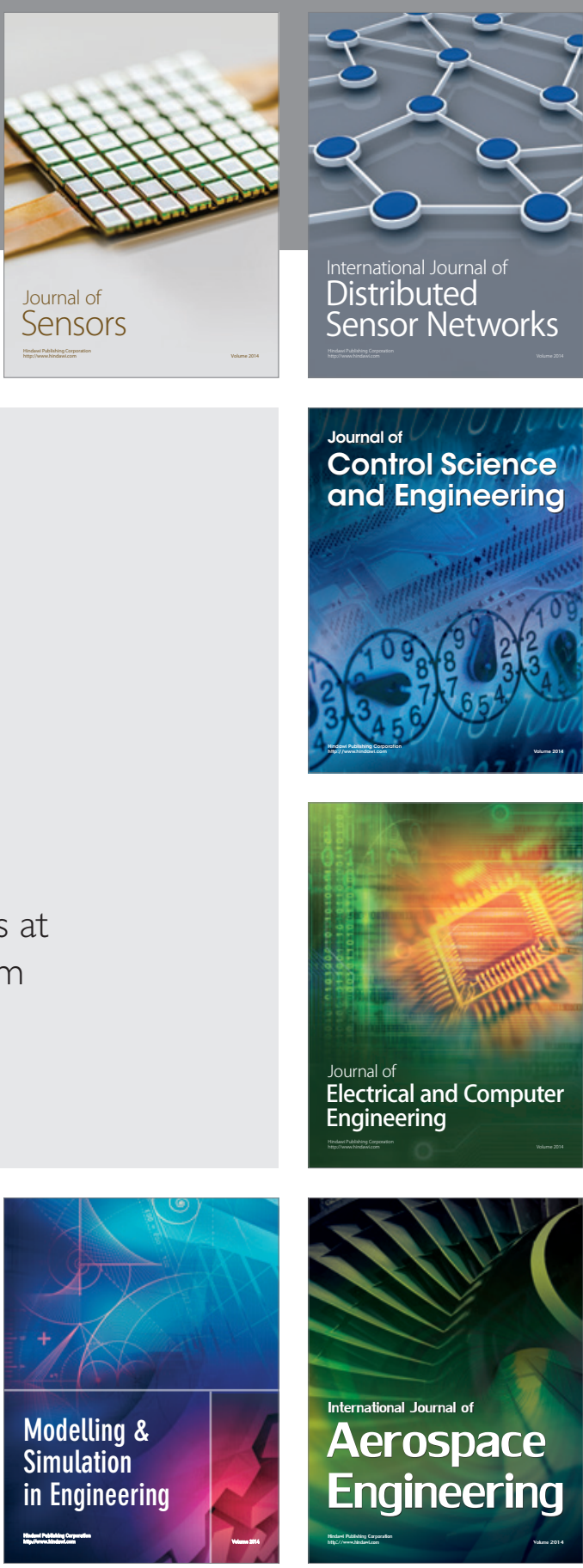

International Journal of

Distributed

Sensor Networks

Journal of

Control Science

and Engineering
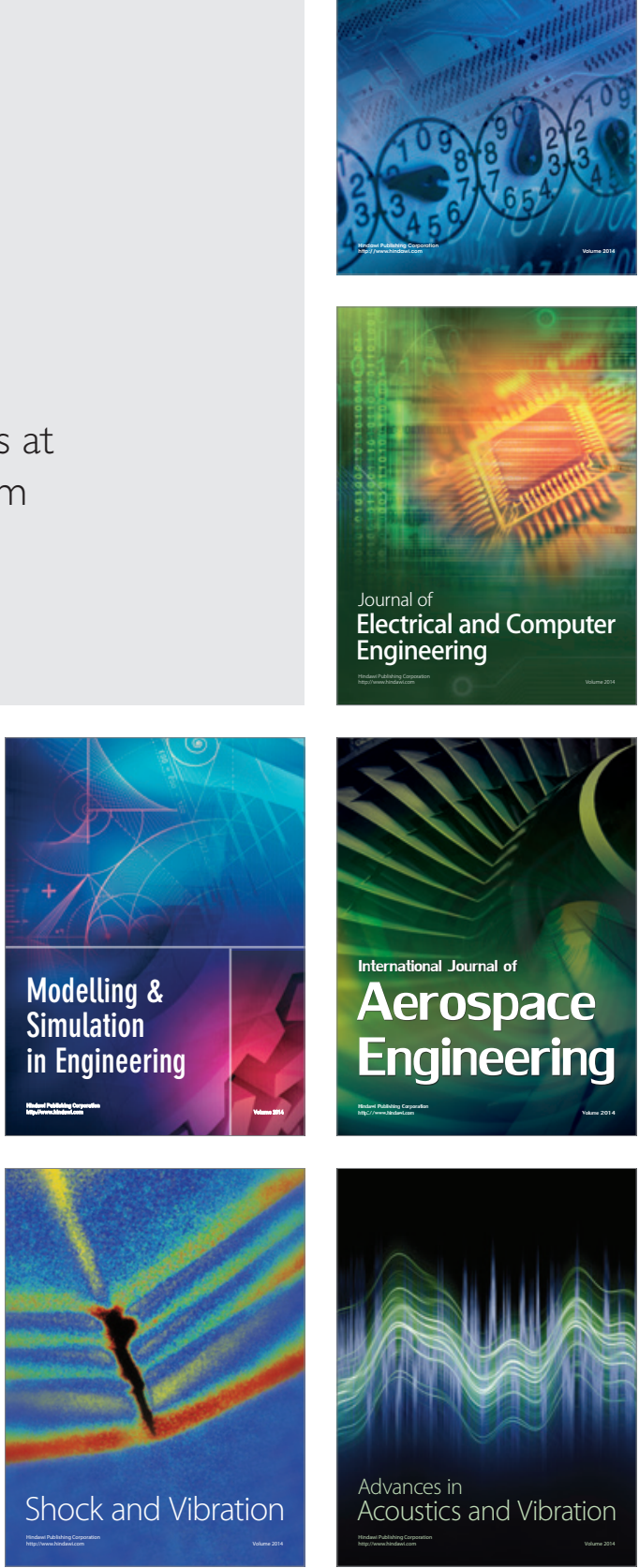